\title{
BUCKLING OF LAMINATED GLASS PLATES USING THE EFFECTIVE THICKNESS CONCEPT
}

M. Aenlle, F. Pelayo*, Miguel Muñiz Calvente, M.J. Lamela-Rey

Department of Construction and Manufacturing Engineering, University of Oviedo, Campus de Gijón, Zona Oeste, Edificio 7, 33203, Gijón, Spain.

*corresponding author; E-mail: fernandezpelayo@uniovi.es

Phone: +34985 182057, Fax: +34985182433

\begin{abstract}
Laminated glass is a sandwich material composed of two or more glass layers and one or more polymeric interlayers. The mechanical behaviour of glass is commonly considered linear-elastic whereas most laminated interlayers exhibit a viscoelastic behaviour. The mechanical behaviour of laminated glass elements is governed by the material properties of the interlayer, which means that the critical buckling loads of laminated glass panels are time and temperature dependent. In this paper, a simplified method to calculate the buckling critical load of rectangular laminated glass plates is presented, which uses the analytical solutions of elastic monolithic plates, the quasi-elastic approximation and the effective thickness concept. The analytical solutions are validated by numerical simulations on simply supported laminated glass plates subject to different loading conditions.
\end{abstract}

\section{KEYWORDS}

Laminated glass, structural composites, PVB, bucking, structural stability, viscoelasticity. 
NOMENCLATURE

$D_{1}=\frac{E H_{1}^{3}}{12\left(1-v_{1}^{2}\right)}$

$D_{3}=\frac{E H_{3}^{3}}{12\left(1-v_{3}^{2}\right)}$

$D_{T}=D_{1}+D_{3}$

$D_{T O T=}=D_{T}\left(1+Y_{P}\right)$

$E_{\text {eff }} \quad$ Effective Young modulus

E Glass Young modulus of glass layers

$E_{2}(t) \quad$ Viscoelastic relaxation tensile modulus for polymeric interlayer

$G_{2}(t) \quad$ Viscoelastic relaxation shear modulus for the polymeric interlayer

$H_{1} \quad$ Thickness of glass layer 1 in laminated glass

$H_{2} \quad$ Thickness of polymeric layer in laminated glass

$H_{3} \quad$ Thickness of glass layer 3 in laminated glass

$H_{T O T}=H_{1}+H_{2}+H_{3}$

$H_{13}=H_{2}+\left(\frac{H_{1}+H_{3}}{2}\right)$

I Second moment of area

$I_{1}=\frac{b H_{1}^{3}}{12}$

$I_{3}=\frac{b H_{3}^{3}}{12}$ 
$I_{T}=I_{1}+I_{3}=b \frac{H_{1}^{3}+H_{3}^{3}}{12}$

$I_{T O T=}=I_{T}(1+Y)$

$K_{2}(t, T) \quad$ Viscoelastic bulk modulus

L Length of a glass beam

$P(t, T) \quad$ Critical load

T Temperature

$T_{0} \quad$ Reference temperature

$Y=\frac{H_{13}^{2} H_{1}}{I_{T}\left(H_{1}+H_{3}\right)}$

$Y_{P}=\frac{H_{13}^{2} \frac{E H_{1}}{\left(1-v^{2}\right)} \frac{E H_{3}}{\left(1-v^{2}\right)}}{\left(D_{1}+D_{3}\right)\left(\frac{E H_{1}}{\left(1-v^{2}\right)}+\frac{E H_{3}}{\left(1-v^{2}\right)}\right)}=\frac{12 H_{1} H_{3} H_{13}^{2}}{\left(H_{1}+H_{3}\right)\left(H_{1}^{3}+H_{3}^{3}\right)}$

\section{LOWERCASE LETTERS}

$a_{T} \quad$ Shift factor

$g(x) \quad$ Shape function in beams

$g(x, y) \quad$ Shape function in plates

$t \quad$ Time

w Deflection

\section{GREEK LETTERS}

$\eta_{2} \quad$ Loss factor of the polymeric interlayer of laminated glass

$v \quad$ Poisson ratio of the glass layers 
$v_{2}(t, T) \quad$ Viscoelastic Poisson ratio of the polymeric interlayer 


\section{INTRODUCTION}

Laminated glass is a sandwich or layered material which consists of two or more plies of monolithic glass with one or more interlayers of a polymeric material which usually show a viscoelastic behaviour, i.e., their mechanical properties are time (or frequency) and temperature dependent [1]. Polyvinyl butyral (PVB) is the most used interlayer material, however the new ionoplastic interlayers improve the mechanical properties of laminated glass for a large range of temperatures [1].

Structural stability is one of the design requirements in laminated glass beams and plates due to their slenderness and brittleness. Due to the fact that the stiffness of the interlayer is temperature and time dependent, the same can be said about the critical load, i.e., the critical load of a laminated glass plate subject to constant compressive loading decreases with time. Most of the analytical models for predicting the buckling of laminated glass plates have been derived from classical sandwich theory formulations $[2,3,4]$ where it is generally assumed that the materials exhibit a linear-elastic behavior and shear deformations occur in the core. The equations for sandwich beams and plates with linearelastic interlayers can be easily extended to viscoelastic interlayers using the correspondence principle $[5,6]$.

In order to facilitate the calculation of laminated glass elements, the viscoelastic solution can be simplified using the quasi-elastic method, which consists of describing the viscoelastic behaviour of the interlayer by an elastic behaviour with parameters that depend on the load duration and temperature $[7,8,9]$. This means that the memory effect of the viscoelastic material is neglected and that the mechanical properties are linearelastic but dependent on time [10].

The concept of effective thickness has been proposed in recent years $[6,7,8]$ based on the quasi-elastic solution, which consists of calculating the thickness (time and temperature dependent) of a monolithic element with bending properties equivalent to those of the laminated one. The effective thickness can then be used in analytical equations and simplified finite element models in place of the layered laminated-glass element [11, 12, 13, 14]. An effective Young modulus [13] can also be formulated from the models developed by Benninson et al [10, 14] and Galuppi and Royer-Carfagni [11], 
which is more attractive to be used in numerical models because a monolithic model with constant thickness is defined, whereas the Young modulus is time and temperature dependent. The effective thickness and the effective Young modulus concepts can be used interchangeably with the same accuracy.

Several analytical models have been proposed for determining the critical load of a simply supported laminated glass beams [15, 16, 17, 18]. Galuppi and Royer-Carfagni [17] developed an analytical model for the buckling of a simply supported laminated glass column with viscoelastic core under a compressive load $P(t)$, which can be time dependent. A full viscoelastic solution is developed but a simpler model was derived using the quasi-elastic approximation [17].

The effect of the boundary conditions in monolithic beams is considered through the buckling ratio $\beta$ (or alternatively with the effective length $L_{e f f}$ ), whereas the stiffness EI is constant. Aenlle et al [19] proposed a simplified method to calculate critical loads in laminated glass beams with different boundary conditions using the Euler theory [20] of monolithic beams, the quasi-elastic solution $[9,10]$ and the effective stiffness, and the effect of the boundary conditions are taken into account through the buckling ratios $\beta$ derived for elastic monolithic beams $[20,21]$. The authors demonstrated that the effective stiffness, the effective thickness and the effective Young's modulus also depend on the boundary conditions and their effect can also be taken into account through the buckling ratio $\beta$. The model was validated by experimental tests and numerical models.

In this paper a simplified method to calculate critical loads in laminated glass plates using the solutions of elastic monolithic plates [20, 21], the quasi-elastic solution [9] and the effective stiffness concept [19] is proposed. In order to validate the model, the critical load of several simply supported laminated glass plates, made of annealed glass plies and PVB interlayer, subject to different loading conditions, were predicted using the simplified model proposed in this paper and validated by numerical simulations carried out with the finite element software ABAQUS [22].It is concluded that the simplified analytical model predict the critical load of simply supported laminated glass plates with an error less than $10 \%$ for all the cases considered in the paper. 


\section{STATE OF THE ART}

\subsection{Sandwich beams with thin faces under static loading}

The displacement of a simply supported sandwich beam with thin faces (see Figure 1) of equal thickness $H_{1}=H_{3}=H$ and Young modulus $E$, core with thickness $H_{2}$ and shear modulus $G_{2}$, spam $L$ and with a central point load $P$ can be found superimposing the bending displacement $w_{1}$ and the shear displacement $w_{2}$ [3], i.e.:

$$
w=w_{1}+w_{2}=w_{1}\left(1+\frac{w_{2}}{w_{1}}\right)
$$

where

$$
\begin{aligned}
& w_{1}=\frac{P L^{3}}{48 E I} \\
& w_{2}=\frac{P L H_{2}}{4 b G_{2} H_{13}^{2}} \\
& E I=\frac{E H^{3}}{6}+\frac{E H H_{13}^{2}}{2} \\
& H_{13}=H+H_{2}
\end{aligned}
$$

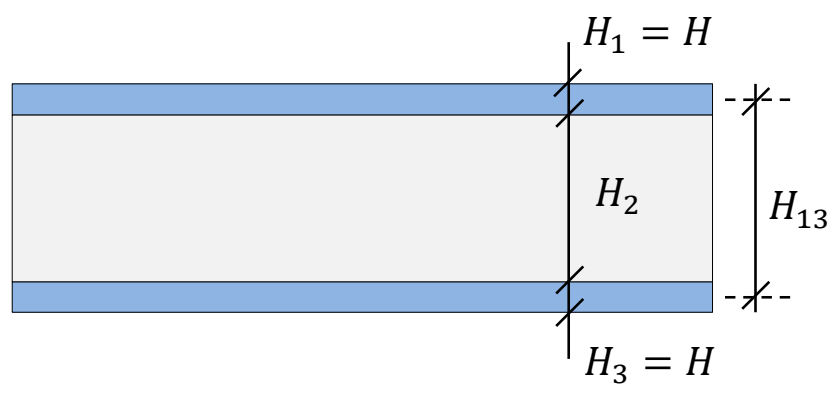

Figure 1. Sandwich beam with two external faces of thicknesses $H=H_{1}=H_{2}$ and one interlayer with thickness $\mathrm{H}_{2}$.

In order to facilitate the calculation of displacements in sandwich beams, an effective stiffness $E I_{\text {eff }}$ to be used with bending monolithic models, can be derived from Eq. (1), i.e: 


$$
\frac{P L^{3}}{48 E I_{\text {eff }}}=\frac{P L^{3}}{48 E I}\left(1+\frac{\frac{P L H_{2}}{4 b G_{2} H_{13}^{2}}}{\frac{P L^{3}}{48 E I}}\right)
$$

which results in:

$$
E I_{e f f}=E I\left(\frac{1}{1+\frac{E I \cdot H_{2}}{G_{2} b H_{13}^{2}} \psi_{\text {thin }}}\right)
$$

Where $\psi_{\text {thin }}$ is a parameter which depends on the loading and boundary conditions. Expressions for the effective stiffness of any statically-determinate symmetrically-loaded sandwich beam can be formulated superimposing the bending and the shear deflections [3]. For a simply supported beam with a central point load $\psi_{\text {thin }}=12 / L^{2}$, whereas $\psi_{\text {thin }}=9.6 / L^{2}$ for a simply supported beam under distributed loading.

\subsection{Sandwich beams with thick faces under static loading}

In the case of sandwich beams with thick faces, the effective stiffness is derived using the same procedure as that used in the previous section and it is given by:

$$
E I_{e f f}=E I\left(\frac{1}{1+\frac{E I \cdot H_{2}}{G_{2} b H_{13}^{2}} \psi_{\text {thick }}}\right)
$$

Where:

$$
\psi_{\text {thick }}=\psi_{\text {thin }}\left(1-\frac{I_{f}}{I}\right)^{2} \gamma
$$

In Eq. (9), $I_{f}$ is the inertia of one of the faces with respect to its own centroidal axis. The expressions of parameters $\psi_{\text {thin }}$ and $\gamma$ for simply supported beams under mid-point concentrated loading and uniformly distributed loading are presented in Table 1, where the parameter $\theta$ is given by [3]: 


$$
\theta=\frac{L}{2} \sqrt{\frac{G_{2} b H_{12}^{2}}{H_{2} E I_{f}\left(1-\frac{I_{f}}{I}\right)}}
$$

Table 1. Parameters $\psi_{\text {thin }}$ and $\gamma$ for simply supported beams.

\begin{tabular}{ccc}
\hline Beam & $\psi_{\text {thin }}$ & $\gamma$ \\
\hline Central point load & $12 / L^{2}$ & $1-\frac{\sinh \theta+\frac{(1-\cosh \theta)}{\tanh \theta+1 / \tanh \theta}}{\theta}$ \\
Distributed load & $9.6 / L^{2}$ & $1+\frac{2}{\theta^{2} \cosh \theta}(1-\cosh \theta)$ \\
\hline
\end{tabular}

If $\mathrm{I}_{\mathrm{f}} \rightarrow 0$, from Eq. (9) it is easily derived that:

$$
\psi_{\text {thick }}=\psi_{\text {thin }}
$$

\subsection{Buckling of a monolithic beam}

The critical load of a linear-elastic monolithic beam with constant cross section and stiffness $E I$, according to the Euler theory, is given by [20, 21]:

$$
N_{c r i t}=\frac{\pi^{2}}{(\beta L)^{2}} E I
$$

Where $\beta$ is the buckling ratio.

If the critical load is calculated by the Energy method [20, 21] with an approximate deflection curve $\mathrm{g}(x)$, the critical load is obtained from:

$$
N_{c r i t}=\frac{\int_{0}^{L} E I^{\prime \prime}(x)^{2} d x}{\int_{0}^{L} g^{\prime}(x)^{2} d x}
$$

From which is inferred that: 


$$
\frac{\pi^{2}}{(\beta L)^{2}}=\frac{\int_{0}^{L} g^{\prime \prime}(x)^{2} d x}{\int_{0}^{L} g^{\prime}(x)^{2} d x}
$$

For a simply supported beam the mode shapes are sinusoidal in shape, i.e.:

$$
g(x)=A \sin \left(\frac{n \pi x}{L}\right)
$$

Substitution of Eq. (15) in Eq. (14) gives for $n=1$ :

$$
\frac{\pi^{2}}{(\beta L)^{2}}=\frac{\pi^{2}}{L^{2}}
$$

From which it is obtained that $\beta=1$. This result coincides with buckling ratio of a simply supported beam.

\subsection{Buckling of sandwich beams with thin faces.}

The critical load of a simply supported sandwich beam with thin faces can be estimated using the expression [3]:

$$
N_{c r i t}=\frac{\pi^{2}}{L^{2}} E I_{e f f}
$$

where

$$
E I_{e f f}=E I\left(\frac{1}{1+\frac{E I \cdot H_{2}}{G_{2} b H_{13}^{2}} \psi_{\text {thin }}}\right)
$$

and

$$
\psi_{\text {thin }}=\frac{\pi^{2}}{L^{2}}
$$


It can be observed that Eqs. (7) and (18) coincide, i.e. the expression of the effective stiffness is the same for static loads and for buckling but with the special feature that the parameters $\psi_{\text {thin }}$ are different in statics and in buckling, for the same boundary conditions.

\subsection{Buckling of sandwich beams with thick faces}

The critical load of a sandwich beam with thin faces can be estimated with Eq. (17) but with a different effective stiffness given by:

$$
E I_{e f f}=E I\left(\frac{1}{1+\frac{E I \cdot H_{2}}{G_{2} b H_{13}^{2}} \psi_{t h i c k}}\right)
$$

where

$$
\psi_{\text {thick }}=\psi_{\text {thin }}\left(\frac{\left(1-\left(\frac{I_{f}}{I}\right)\right)^{2}}{1+\frac{E I_{f} \cdot H_{2}}{G_{2} b H_{12}^{2}} \frac{\pi^{2}}{L^{2}}\left(1-\frac{I_{f}}{I}\right)}\right)
$$

From Eq. (21) it is inferred that:

$$
\psi_{\text {thick }}=\psi_{\text {thin }}
$$

when $I_{f} \rightarrow 0$.

\subsection{Buckling of rectangular monolithic plates}

The critical load of a simply supported rectangular monolithic plate with dimensions $a \times$ $b$, thickness $H$, and subject to uniaxial compression in the "x" direction (see Figure 2) is given by:

$$
N_{x c r i t}=\frac{\pi^{2}}{b^{2}} k D
$$

Where $D$ is the stiffness of the plate: 


$$
D=\frac{E H^{3}}{12\left(1-v^{2}\right)}
$$

and $k$ is a parameter dependent on the boundary conditions, which is expressed as:

$$
k=\left(\frac{m b}{a}+\frac{a n^{2}}{m b}\right)^{2}
$$

where the parameters $m$ and $n$ are the number of half-waves that the plate buckles into the $\mathrm{x}$ and $\mathrm{y}$ directions, respectively.

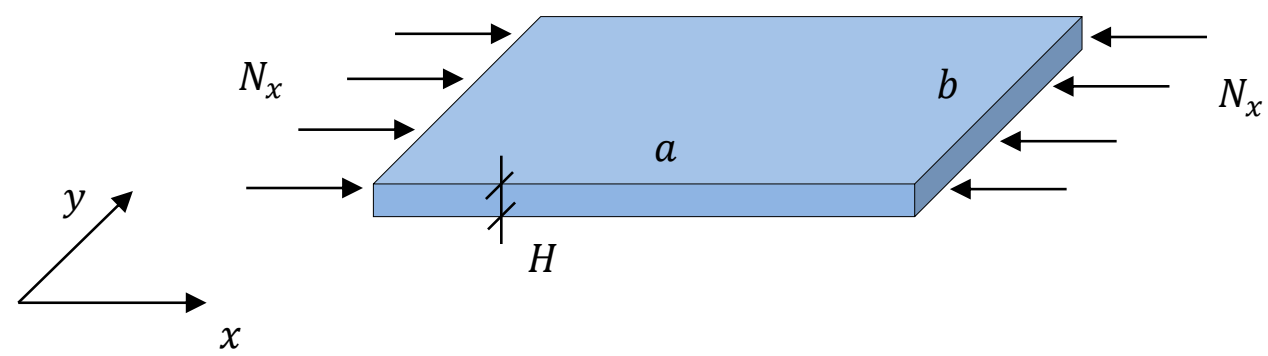

Figure 2. Rectangular monolithic plate subject to a compressive uniaxial loading in the $x$ direction.

On the other hand, the critical loading of a rectangular plate subject to normal loadings $N_{x}, N_{y}$ and $N_{x y}$ (see Figure 3), can also be calculated by the Energy method assuming an approximate buckling mode shape $g(x, y)$, which satisfies the boundary conditions $[20,21]$. The total potential energy of the system consists of two parts, the strain energy due to bending $U_{b}$, which can be calculated by means of the expression:

$$
\begin{aligned}
U_{b}=\frac{D}{2} \int_{0}^{a} \int_{0}^{b}\left[\left(\frac{\partial^{2} g(x, y)}{\partial x^{2}}+\frac{\partial^{2} g(x, y)}{\partial y^{2}}\right)^{2}\right. \\
\left.\quad-2(1-v)\left(\frac{\partial^{2} g(x, y)}{\partial x^{2}} \frac{\partial^{2} g(x, y)}{\partial y^{2}}-\left(\frac{\partial^{2} g(x, y)}{\partial x \partial y}\right)^{2}\right)\right] d x d y
\end{aligned}
$$

and the potential energy of the external loads $U_{N}$ which is given by:

$$
U_{N}=-\frac{1}{2} \int_{0}^{a} \int_{0}^{b}\left[N_{x}\left(\frac{\partial g(x, y)}{\partial x}\right)^{2}+N_{y}\left(\frac{\partial g(x, y)}{\partial y}\right)^{2}+2 N_{x y} \frac{\partial g(x, y)}{\partial x} \frac{\partial g(x, y)}{\partial y}\right] d x d y
$$




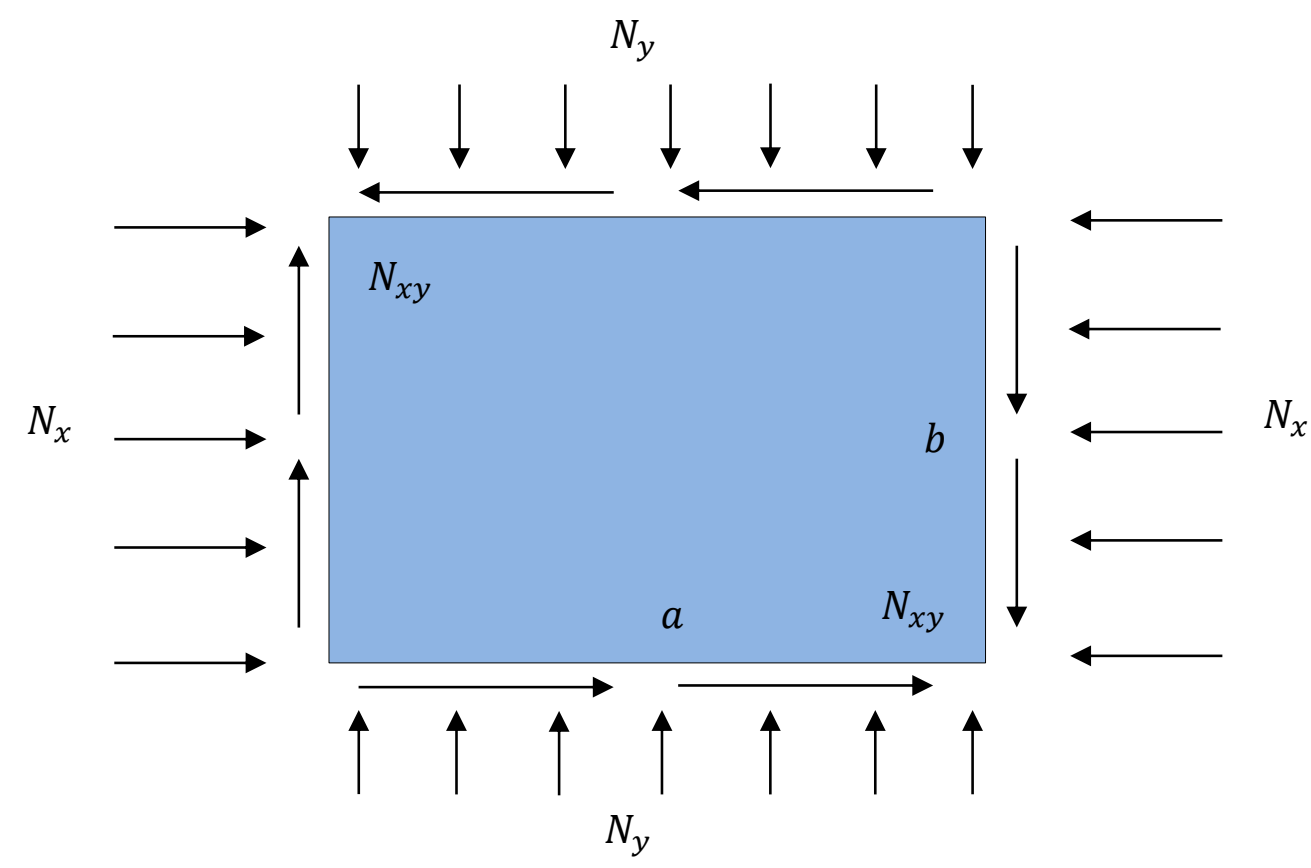

Figure 3: Rectangular monolithic plate subject to loadings $N_{x}, N_{y}$ and $N_{x y}$.

Using the notation:

$$
\begin{array}{ll}
\frac{\partial^{2} g(x, y)}{\partial x^{2}}=g_{x}^{\prime \prime} & \frac{\partial g(x, y)}{\partial x}=g_{x}^{\prime} \\
\frac{\partial^{2} g(x, y)}{\partial y^{2}}=g_{y}^{\prime \prime} & \frac{\partial g(x, y)}{\partial y}=g_{y}^{\prime} \\
\frac{\partial^{2} g(x, y)}{\partial x \partial y}=g_{x y}^{\prime \prime} &
\end{array}
$$

Eqs. (26) is expressed as:

$$
U_{b}=\frac{D}{2} \int_{0}^{a b} \int_{0}^{b}\left[\left(g_{x}^{\prime \prime}+g_{y}^{\prime \prime}\right)^{2}-2(1-v)\left(g_{x}^{\prime \prime} g_{y}^{\prime \prime}-\left(g_{x y}^{\prime \prime}\right)^{2}\right)\right] d x d y
$$

and Eq. (27) as: 


$$
U_{N}=-\frac{1}{2} \int_{0}^{a b}\left[\int_{0}^{b}\left(g_{x}^{\prime}\right)^{2}+N_{y}\left(g_{y}^{\prime}\right)^{2}+2 N_{x y} g_{x}^{\prime} g_{y}^{\prime}\right] d x d y
$$

The critical values of the forces can be found minimizing the total energy $\Pi$, i.e. minimizing the equation:

$$
\Pi=U_{b}+U_{N}
$$

\subsection{Buckling of sandwich plates with thin faces}

The critical load of a rectangular sandwich plate simply supported along the four edges, with thin faces of thickness $H$, core with shear modulus $G_{2}$ and thickness $H_{2}$, dimensions $a \times b$ and compressed in the $\mathrm{x}$ direction is given by [3]:

$$
N_{x c r i t}=\frac{\pi^{2}}{b^{2}} k D_{e f f}
$$

where

$$
\begin{aligned}
& k=\left(\frac{m b}{a}+\frac{a n^{2}}{m b}\right)^{2} \\
& D_{\text {eff }}=\frac{D}{1+\frac{E H_{2} H}{2 G_{2}\left(1-v^{2}\right)} \psi_{\text {thin }}} \\
& D=\frac{E H H_{13}^{2}}{2\left(1-v^{2}\right)} \\
& \psi_{\text {thin }}=\frac{\pi^{2}}{b^{2}}\left(n^{2}+m^{2} \frac{b^{2}}{a^{2}}\right)
\end{aligned}
$$




\subsection{Buckling of sandwich plates with thick faces}

In the case of a rectangular sandwich plate with thick faces, with the same geometry as that described in section 2.7, and compressed in the $\mathrm{x}$ direction, the critical load can be predicted with Eq. (32) but using the following effective stiffness given by:

$$
D_{e f f}=D\left(\frac{1}{1+\frac{E H_{2} H}{2 G_{2}\left(1-v^{2}\right)} \psi_{t h i c k}}+\frac{H^{2}}{3 H_{12}^{2}}\right)
$$

Where the parameters $k, D$ are given by Eqs. (33) and (35), respectively, and $\psi_{\text {thick }}=$ $\psi_{\text {thin }}$

\subsection{Laminated glass beams under static loading}

The concept of effective thickness for the calculation of deflections in laminated glass beams under static loads was proposed by Benninson et al. [1, 14] based on a previous work of Wölfel [13]. From the model proposed by Benninson et al. [1, 6], an effective stiffness for a laminated-glass beam subject to a static loading can be formulated, which is expressed as:

$$
E I(t, T)_{e f f}=E I_{T}\left(1+\frac{Y}{1+\frac{E H_{1} H_{2} H_{3}}{G_{2}(t, T)\left(H_{1}+H_{3}\right)} \frac{\gamma}{L^{2}}}\right)
$$

Benninson et al. assume $\gamma=9.6$ for all the boundary conditions although in the Wölfel's formulation this is associated to a simply supported beam under uniformly distributed load. The Parameter $Y$ in Eq. (38) is a constant coefficient that relates the monolithic limit $E I_{T O T}$ and the layered limit $E I_{T}$ of the effective stiffness $E I(t, T)_{e f f}$, by means of the expression:

$$
1+Y=\frac{E I_{T O T}}{E I_{T}}
$$

Later, Galuppi and Royer-Carfagni [11] derived new equations for the deflection effective thickness using a variational approach and assuming that the deflection shape of the laminated glass beam coincide with that of a monolithic beam with the same load and boundary conditions, i.e. ,the deflection of the beam is assumed as: 


$$
w(x, t, T)=-\frac{g(x)}{E I(t, T)_{e f f}}
$$

where $\mathrm{g}(\mathrm{x})$ is a shape function that takes the form of the elastic deflection of a monolithic beam, with constant cross section under the same load and boundary conditions as the laminated glass beam, and $E I(t)_{e f f}$ is the bending stiffness of the laminated glass beam given by:

$$
E I(t, T)_{e f f}=E I_{T}\left(1+\frac{Y}{1+\frac{E H_{1} H_{2} H_{3}}{G_{2}(t, T)\left(H_{1}+H_{3}\right)} \psi_{B}}\right)
$$

where the parameter $\psi_{B}$ is calculated with the equation:

$$
\psi_{B}=\frac{\int_{0}^{L} g^{\prime \prime}(x)^{2} d x}{\int_{0}^{L} g^{\prime}(x)^{2} d x} ; \quad 0 \leq \mathrm{x} \leq \mathrm{L}
$$

The authors derived $\psi_{B}=10 / \mathrm{L}^{2}$ for a beam under concentrated load and $\psi_{B}=\frac{168}{17 L^{2}}=$ $\frac{9.882}{L^{2}}$ for a beam under distributed load. These parameters $\psi_{B}$ coincide with those proposed for sandwich beams $\left(\psi_{\text {thin }}\right)$ under the same load and same boundary conditions.

\subsection{Buckling of laminated glass beams}

Blaauwendraad [15] proposed a formula for the buckling force of a simply supported laminated glass column, which is expressed as:

$$
N_{\text {crit }}(\mathrm{t}, \mathrm{T})=\frac{\pi^{2} E I_{T}}{L^{2}}+\frac{H_{0}^{2}}{\frac{L^{2}}{\pi^{2} E H_{1}}+\frac{L^{2}}{\pi^{2} E H_{3}}+\frac{H_{2}}{G_{2}(t, T)}}
$$

As it is pointed out by the author, this equation coincides with the equation derived by Satler and Stein [16] for sandwich panels. 
Feldmann et al. [18] proposed to calculate the critical load of a simply supported beam with the Euler Theory but using an effective stiffness $E I(t, T)_{e f f}$, i.e.:

$$
N_{c r i t}(\mathrm{t}, \mathrm{T})=\frac{\pi^{2} E I(t, T)_{e f f}}{L^{2}}
$$

where

$$
E I(t, T)_{e f f}=E I_{T}\left(1+\frac{Y}{1+\frac{E H_{1} H_{2} H_{3}}{G_{2}(t, T)\left(H_{1}+H_{3}\right)} \frac{\pi^{2}}{L^{2}}}\right)
$$

Galuppi and Royer-Carfagni [17] developed an analytical model for the buckling of simply supported laminated three-layered composite beams with viscoelastic core and under a compressive load $P(t)$, which can be time dependent. The authors derived a simple model using the quasi-elastic approximation which neglects the memory effect and assuming that the deflection of the beam is given by:

$$
w(x, t, T)=a(t, T) \sin \left(\frac{\pi x}{L}\right)
$$

The critical load is given by:

$$
P_{c r i t}(\mathrm{t}, \mathrm{T})=\frac{\pi^{2}}{L^{2}} \mathrm{EI}_{\mathrm{T}}\left(1+\frac{Y}{1+\frac{E H_{1} H_{2} H_{3}}{\mathrm{G}_{2}(t, T)\left(H_{1}+H_{3}\right)} \frac{\pi^{2}}{L^{2}}}\right)
$$

It can be easily demonstrated that Eq. (47) coincides with Eq. (44) developed by Blaauwendraad [15] and with Eq. (43) derived by Feldmann et al. [18].

Aenlle et al. [19] proposed to calculate the critical load of a laminated glass beam using the equation of the critical load of a linear-elastic monolithic beam according to the Euler theory, but using an effective stiffness, i.e.:

$$
N_{c r i t}(\mathrm{t}, \mathrm{T})=\frac{\pi^{2}}{\beta^{2} L^{2}} \mathrm{EI}(\mathrm{t}, \mathrm{T})_{\mathrm{eff}}
$$


where $\mathrm{EI}(\mathrm{t}, \mathrm{T})_{\text {eff }}$ is given by Eq. (41). Due to the fact that the deflection of a beam in buckling differs from that of a beam under static loading, new parameters $\psi_{B}$ have to be calculated for buckling. In Table 2 , the values of $\psi_{B}$ for the buckling of the most common boundary conditions are presented where it has been assumed that the buckling mode shapes of the laminated glass beams are equal to those of an elastic monolithic beam with the same boundary conditions.

Table 2. $\psi_{B}$ for the first buckling mode shape of a beam

\begin{tabular}{ccc}
\hline Boundary condition & $g(x)$ & $\psi_{B}$ \\
\hline Simply supported & $A \sin \left(\frac{\pi x}{L}\right)$ & $\frac{\pi^{2}}{L^{2}}$ \\
Cantilever & $A\left(1-\cos \left(\frac{\pi x}{2 L}\right)\right)$ & $\frac{\pi^{2}}{4 L^{2}}$ \\
Fixed-pinned & $A\left(\frac{x}{L}+1.02 \cdot \sin \left(\frac{\pi x}{0.699 L}\right)\right)$ & $\frac{\pi^{2}}{0.4886 L^{2}}$ \\
Fixed-fixed & $A\left(1-\cos \left(\frac{2 \pi x}{L}\right)\right)$ & $\frac{\pi^{2}}{0.25 L^{2}}$ \\
\hline
\end{tabular}

From Table 2, it can be easily inferred that the parameter $\psi_{B}$ is related to the buckling ratio $\beta$ by means of the equation:

$$
\psi_{B}=\frac{\pi^{2}}{(\beta L)^{2}}
$$

and Eq. (48) can be expressed as:

$$
N_{c r i t}(\mathrm{t}, \mathrm{T})=\psi_{B} \mathrm{EI}(\mathrm{t}, \mathrm{T})_{\text {eff }}
$$

Eqs. (48) and (50) are general equations to calculate the critical load of a laminated glass beam, and they can be considered a generalization of Eq. (47), derived for simply supported beams to any boundary condition through the buckling ratio $\beta$. 


\subsection{Buckling of laminated glass Plates}

Amadio and Bedon [24, 25] developed an analytical model for the buckling of laminated glass plates based on the Euler theory and using an effective stiffness $D(t, T)_{\text {eff }}$ :

$$
N_{c r i t}=\frac{\pi^{2}}{b^{2}} k \mathrm{D}(\mathrm{t}, \mathrm{T})_{\mathrm{eff}}
$$

where $\mathrm{D}(\mathrm{t}, \mathrm{T})_{\text {eff }}$ is given by:

$$
\mathrm{D}(\mathrm{t}, \mathrm{T})_{\mathrm{eff}}=\frac{E t_{e q}^{3}(\mathrm{t}, \mathrm{T})}{12\left(1-v^{2}\right)}
$$

In Eq. (52) $t_{e q}(\mathrm{t}, \mathrm{T})$ is an equivalent thickness derived from Eq. (38). Due to the fact that Eq. (38) provides the effective stiffness for a laminated glass beam, it is corrected through a parameter $\beta$ dependent on the ratio $a / b$.

The accuracy of Eq. (51) was studied in laminated glass panels in-plane compressed in one direction [24] and subject to in-plane shear loading [25].

\section{CRITICAL LOAD OF RECTANGULAR LAMINATED GLASS PLATES}

In this paper, it is proposed to calculate the critical load of a laminated glass plate using the equations of the critical load of a linear-elastic monolithic thin plate, but with an effective stiffness $D(t, T)$ eff i.e.:

$$
N_{c r i t}=\frac{\pi^{2}}{b^{2}} k \mathrm{D}(\mathrm{t}, \mathrm{T})_{\mathrm{eff}}
$$

Where $\mathrm{k}$ is a parameter dependent on the boundary conditions and on the ratio $\gamma=\frac{a}{b}[20$, 21].

With Respect to the effective stiffness $\mathrm{D}(\mathrm{t}, \mathrm{T})_{\text {eff }}$, the expression formulated by Galuppi and Royer Carfagni for rectangular plates under static loadings is considered, i.e.: 


$$
D(t, T)_{e f f}=D_{T}\left(1+\frac{Y_{P}}{1+\frac{12 D_{1} D_{3} H_{2}}{\mathrm{G}_{2}(\mathrm{t}, \mathrm{T})\left(D_{1} H_{3}^{2}+D_{3} H_{1}^{2}\right)} \psi_{P}}\right)
$$

where $Y_{P}$ is a constant parameter dependent on the material properties and thicknesses of the laminated plate layers through the expression:

$$
Y_{P}=\frac{H_{13}^{2} \frac{E H_{1}}{\left(1-v^{2}\right)} \frac{E H_{3}}{\left(1-v^{2}\right)}}{\left(D_{1}+D_{3}\right)\left(\frac{E H_{1}}{\left(1-v^{2}\right)}+\frac{E H_{3}}{\left(1-v^{2}\right)}\right)}
$$

and the parameter $\psi_{P}$ is given by:

$$
\psi_{P}=\frac{\iint_{0 \quad 0}^{a b}\left[\left(g_{x}^{\prime \prime}+g_{y}^{\prime \prime}\right)^{2}-2(1-v)\left(g_{x}^{\prime \prime} g_{y}^{\prime \prime}-\left(g_{x y}^{\prime \prime}\right)^{2}\right)\right] d x d y}{\iint_{00}^{a b}\left[\left(g_{x}^{\prime}\right)^{2}+\left(g_{y}^{\prime}\right)^{2}\right] d x d y}
$$

where $g(x, y)$ is the buckling mode shape of an elastic monolithic plate with constant cross section under the same boundary conditions of the problem at hand.

With respect to parameter $k$, values for the most common boundary conditions can be found in the literature [20,21].

If the expressions of $D_{1}$ and $D_{3}$ are substituted in Eqs. (54) and (55), they become:

$$
D(t, T)_{e f f}=D_{T}\left(1+\frac{Y_{P}}{1+\frac{E}{\left(1-v^{2}\right)} \frac{H_{1} H_{3} H_{2}}{\mathrm{G}_{2}(\mathrm{t}, \mathrm{T})\left(H_{1}+H_{3}\right)} \psi_{P}}\right)
$$

and 


$$
Y_{P}=\frac{12 H_{1} H_{3} H_{12}^{2}}{\left(H_{1}+H_{3}\right)\left(H_{1}^{3}+H_{3}^{3}\right)}
$$

respectively.

\subsection{Methodology}

The critical load of a laminated glass plate can be calculated with Eq. (53) using appropriate parameters $k$ and $\psi_{P}$. We assume that the parameter $k$ consider in Eq. (53) is the same as that consider in monolithic plates, which means that the buckling mode shape is the same for the monolithic and the laminated glass plate. This also means that the critical load of a laminated glass plate with dimensions $a \times b$ can also be calculated by means of the equation:

$$
N_{c r i t}(\mathrm{t}, \mathrm{T})=N_{c r i t-M O N} \frac{\mathrm{D}(\mathrm{t}, \mathrm{T})_{\mathrm{eff}}}{\mathrm{D}}
$$

Where $N_{\text {crit-MON }}$ is the buckling load of a monolithic plate with same dimensions $a \times b$ and stiffness $D$. The following procedure can be followed:

1) To assemble a finite element monolithic model with thickness $H_{T O T}$, dimensions $a \times$ $b$ and material properties $E$ and $\nu$.

2) To calculate the buckling load of the finite element monolithic model. Alternatively, $N_{\text {crit-MON }}$ can be calculated using the analytical equations proposed in the literature [20, 21] for elastic monolithic plates.

3) To calculate the effective stiffness $\mathrm{D}(\mathrm{t}, \mathrm{T})_{\text {eff }}$. Previously, the parameter $\psi_{P}$ must be calculated or taking from the literature [3].

4) To predict the critical load by means of Eq. (59)

If the monolithic and the laminated glass models have the same total thickness $H_{T O T}$, the critical load can also be calculated with the equation:

$$
N_{c r i t}(\mathrm{t}, \mathrm{T})=N_{c r i t-M O N} \frac{\mathrm{E}(\mathrm{t}, \mathrm{T})_{\mathrm{eff}}}{\mathrm{E}}
$$


where:

$$
\mathrm{E}(\mathrm{t}, \mathrm{T})_{\mathrm{eff}}=\frac{E\left(H_{1}^{3}+H_{3}^{3}\right)}{H_{T o t}^{3}}\left(1+\frac{Y_{P}}{1+\frac{E H_{1} H_{2} H_{3}}{G_{2}(t, T)\left(H_{1}+H_{3}\right)} \psi_{P}}\right)
$$

is an effective Young modulus.

Eqs. (59) and (60) show that the critical load of a laminated glass plate can be predicted using a monolithic model with the same dimensions $a \times b$ and the same boundary conditions as the laminated plate. Therefore, the assembly of a layered model can be avoided.

An alternative consists of assembling a monolithic model with constants thickness but defining a time and temperature dependent Young modulus given by $E(t, T)_{\text {eff }}$.

\section{EXAMPLES OF APPLICATION}

Three different cases of rectangular laminated glass plates simply supported along the fourth edges, are now examined using different configurations of loading and dimensions $a$ and $b$. The elastic properties used for both glass and PVB layers are presented in Table 3. The mechanical behaviour of the PVB interlayers was considered viscoelastic in terms of Prony series and the data used in this paper was obtained in previous works [27].

Table 3. Material properties for glass and PVB [27].

\begin{tabular}{|c|c|c|c|c|c|c|c|}
\hline \multicolumn{3}{|c|}{$\begin{array}{c}\text { Glass } \\
\left(H_{1}=H_{3}=4 \mathrm{~mm}\right)\end{array}$} & \multicolumn{5}{|c|}{$\begin{array}{c}\text { PVB } \\
\left(H_{2}=0.38 \mathrm{~mm}\right)\end{array}$} \\
\hline $\begin{array}{c}\mathrm{E} \\
\text { (Young's } \\
\text { Modulus) } \\
\text { [GPa] }\end{array}$ & $\begin{array}{c}v \\
\text { (Poisson's } \\
\text { ratio) }\end{array}$ & $\begin{array}{c}\rho \\
\text { (Density) } \\
{\left[\mathrm{kg} / \mathrm{m}^{3}\right]}\end{array}$ & $\begin{array}{c}\mathrm{G}_{0} \\
\text { (Instantaneous } \\
\text { shear modulus) } \\
{[\mathrm{GPa}]}\end{array}$ & $\begin{array}{c}\mathrm{K} \\
\text { (Bulk } \\
\text { Modulus) } \\
{[\mathrm{GPa}]}\end{array}$ & $\begin{array}{c}v \\
\text { (Poisson's } \\
\text { ratio) }\end{array}$ & $\begin{array}{c}\rho \\
\text { (Density) } \\
{\left[\mathrm{kg} / \mathrm{m}^{3}\right]}\end{array}$ & $\begin{array}{cc}C_{1} \quad C_{2} \\
\text { (WLF: Tref }=20 \mathrm{C} \text { ) }\end{array}$ \\
\hline 72 & 0.22 & 2500 & 0.3696 & 2 & 0.44 & 1030 & $12.60 \quad 74.46$ \\
\hline
\end{tabular}

The critical load predicted with the analytical Eq. (53) is always compared with the results obtained with a finite element model (FEM) assembled in ABAQUS. 
In the FEM, 3D linear shell continuum elements (SC8R) were used for the glass layers whereas the PVB layers were meshed with 3D linear hexahedral elements (C3D8R). This meshing technique has been demonstrated to be adequate to reproduce the laminated glass behaviour with a relatively low computational time [27, 28]. The material properties considered in the simulations were the same as those used in the analytical predictions (Table 3) but modelling the PVB interlayer as a linear elastic material. The buckling load was calculated iteratively for each considered time $t=t_{i}$ being the interlayer Young's modulus $\left.E_{t}=E_{t}\left(t_{i}, T\right)\right)$ and the Poisson ratio $v_{t}=0.44$ [29]. The same temperature $T=$ $20^{\circ} \mathrm{C}$ was considered for both the numerical simulations and the analytical predictions.

\subsection{Simply supported plate under uniaxial compression.}

The first case studied in this paper is a rectangular simply supported laminated glass plate compressed in the x direction with the load $N_{x}$ (force per unit length) i.e. $N_{y}=0$ and $N_{x y}=0$ (see Figure 2). In the case of elastic simply supported plates the buckling mode shape can be represented by the double series [20,21]:

$$
g(x, y)=\sum_{m=1}^{\infty} \sum_{n=1}^{\infty} A_{m n} \sin \left(\frac{m \pi x}{a}\right) \sin \left(\frac{n \pi y}{b}\right)
$$

Using the Energy method $[20,21]$ with an approximate buckling mode shape $g(x, y)$ and considering $N_{y}=0$ and $N_{x y}=0$ in Eq. (31), the critical load can be obtained minimizing the equation:

$$
N_{x c r i t}=\mathrm{D}(\mathrm{t}, \mathrm{T}) \operatorname{eff}_{\frac{1}{a b}[} \frac{\int_{0}^{a}\left[\left(g_{x}^{\prime \prime}+g_{y}^{\prime \prime}\right)^{2}-2(1-v)\left(g_{x}^{\prime \prime} g_{y}^{\prime \prime}-\left(g_{x y}^{\prime \prime}\right)^{2}\right)\right] d x d y}{\iint_{00}^{a b}\left(g_{x}^{\prime}\right)^{2} d x d y}
$$

which results in:

$$
N_{x c r i t}=\pi^{2} b^{2} \mathrm{D}(\mathrm{t}, \mathrm{T})_{\mathrm{eff}} \frac{\sum_{m=1}^{\infty} \sum_{n=1}^{\infty} A_{m n}^{2}\left(\frac{m^{2} b}{a}+\frac{a n^{2}}{b}\right)^{2}}{\sum_{m=1}^{\infty} \sum_{n=1}^{\infty} m^{2} A_{m n}^{2}}
$$

Eq. (64) becomes a minimum [20,21] if all coefficients $A_{m n}$, except one, are taken equal to zero. This means that each mode shape is given by: 


$$
g(x, y)=A_{m n} \sin \left(\frac{m \pi x}{a}\right) \sin \left(\frac{n \pi y}{b}\right)
$$

Identifying Eq. (53) and Eq. (64) it is derived that:

$$
\frac{\pi^{2} k}{b^{2}}=\frac{\iint_{00}^{a} b\left[\left(g_{x}^{\prime \prime}+g_{y}^{\prime \prime}\right)^{2}-2(1-v)\left(g_{x}^{\prime \prime} g_{y}^{\prime \prime}-\left(g_{x y}^{\prime \prime}\right)^{2}\right)\right] d x d y}{\iint_{00}^{a b}\left(g_{x}^{\prime}\right)^{2} d x d y}
$$

If Eq. (65) is substituted in Eq. (66), the later becomes:

$$
\frac{\pi^{2} k}{b^{2}}=\frac{\pi^{2}}{b^{2}} \frac{\left(\frac{m^{2} b}{a}+\frac{a n^{2}}{b}\right)^{2}}{m^{2}}
$$

and parameter $\mathrm{k}$ is given by:

$$
k=\left(\frac{m b}{a}+\frac{a n^{2}}{m b}\right)^{2}
$$

On the other hand, substitution of Eq. (65) in Eq. (56) leads to:

$$
\psi_{P}=\frac{\pi^{2}}{b^{2}}\left(n^{2}+\frac{m^{2} b^{2}}{a^{2}}\right)
$$

From Eqs. (68) and (69) is inferred that the parameters $\pi^{2} k / b^{2}$ and $\psi_{P}$ are different (except for same particular cases), contrary to laminated glass beams where

$$
\psi_{B}=\frac{\pi^{2}}{(\beta L)^{2}}
$$

It must also be remarked that the parameter $\psi_{P}$ given by Eq. (69) for a simply supported laminated glass plate loaded in the " $\mathrm{x}$ " direction is equal to the paremeter $\psi_{\text {thin }}$ (Eq. (36)) for a simply supported sandwich plate subjected to the same loading.

If $\mathrm{D}(\mathrm{t}, \mathrm{T})_{\mathrm{eff}}$ is expressed as: 


$$
D(t, T)_{e f f}=\frac{D_{T O T}}{1+Y_{P}}\left(1+\frac{Y_{P}}{1+\frac{12 D_{1} D_{3} H_{2}}{\mathrm{G}_{2}(\mathrm{t}, \mathrm{T})\left(D_{1} H_{3}^{2}+D_{3} H_{1}^{2}\right)} \psi_{P}}\right)
$$

The critical load can also be expressed as [3]:

$$
N_{x c r i t}=\frac{\pi^{2}}{b^{2}} k_{1} \mathrm{D}_{\mathrm{TOT}}
$$

Where the new parameter $k_{1}(t, T)$ depends on the ratio $\gamma=a / b$ through the parameters $k$ and $\psi_{P}$, and on the thicknesses and material properties of the glass and viscoelastic layers, and it is expressed as [3]:

$$
k_{1}(t, T)=\frac{k}{1+Y_{P}}\left(1+\frac{Y_{P}}{1+\frac{12 D_{1} D_{3} H_{2}}{\mathrm{G}_{2}(\mathrm{t}, \mathrm{T})\left(D_{1} H_{3}^{2}+D_{3} H_{1}^{2}\right)} \psi_{P}}\right)
$$

If Eqs. (68) and (69) are substituted in Eq. (73), the later becomes:

$$
k_{1}(t, T)=\frac{\left(\frac{m b}{a}+\frac{a n^{2}}{m b}\right)^{2}}{1+Y_{P}}\left(1+\frac{Y_{P}}{1+\frac{12 D_{1} D_{3} H_{2}}{\mathrm{G}_{2}(\mathrm{t}, \mathrm{T})\left(D_{1} H_{3}^{2}+D_{3} H_{1}^{2}\right)} \frac{\pi^{2}}{b^{2}}\left(n^{2}+\frac{m^{2} b^{2}}{a^{2}}\right)}\right)
$$

Since the critical value of $N_{x}$ is the smallest value that satisfy Eq. (64), the values of $m$ and $n$ that minimize Eq. (64) must be determined. The value of $N_{x}$ increases as $n$ increases and therefore $n=1$, i.e., the plate buckles in a single half wave in the y direction. Since a simply supported plate must buckle into a whole number of half-waves, m must be an integer $[20,21]$. To determine the buckling pattern in the $\mathrm{x}$ direction the variation of $k_{1}$ with the ratio $a / b$ for different values of $m$ must be consider. Moreover, due to the fact that the shear stiffness $G_{2}(t, T)$ is not constant but it depends on time and temperature, the parameter $k_{1}$ will also vary with $\mathrm{G}_{2}(\mathrm{t}, \mathrm{T})$. This means that the number of half-waves 
$\mathrm{m}$ in which the plate buckles into may not be constant but it might change with time and this fact has to verified before predicting the critical loading of a plate [3].

In order to validate the equations and parameters presented in this section, the critical load $N_{\text {xcrit }}$ of a simply supported rectangular laminated glass plate with three different configurations $a=b, a=0.5 b$ and $a=2 b$, respectively were predicted with Eq. (53). The parameters, $m, n, k$ and $\psi_{P}$ corresponding to the three configurations are shown in Table 4, together with the corresponding mode shape obtained with a finite element model. The parameter $\psi_{P}$ can also be expressed as:

$$
\psi_{P}=\frac{\pi^{2}}{b^{2}} k_{\psi}
$$

The values of $k_{\psi}$ are presented in Table 4 .

Table 4. Parameters $k$ and $\psi_{P}$ for a simply supported laminated glass plate with different ratios $a / b$.

\begin{tabular}{|l|l|l|l|l|l|l|l|l|}
\hline $\mathrm{a}$ & $\mathrm{b}$ & $\frac{a}{b}$ & $\mathrm{~m}$ & $\mathrm{n}$ & $\mathrm{k}$ & $\psi_{P}$ & $k_{\psi}$ & Mode shape \\
\hline 1 & 2 & .5 & 1 & 1 & 6.25 & 12.34 & 5 & \\
\hline $\mathrm{m}]$ & & & & & & & & \\
\hline 2 & 2 & 1 & 1 & 1 & 4 & 4.93 & 2 & \\
\hline
\end{tabular}




\begin{tabular}{|l|l|l|l|l|l|l|l|l|}
\hline 2 & 1 & 2 & 2 & 1 & 4 & 19.74 & 2 & \\
\hline
\end{tabular}

The parameter $k_{1}$ for this simply supported laminated glass plate considering $n=1, m=$ $1,2,3$ and ratios $0.3<a / b<3$ is shown in Figure 4. The figure confirms that the values taken for $m$ in Table 4 are correct, i.e., they are valid for all the range of the shear parameter G2 (see Figure 5) [27]) where $2 \cdot 10^{5}<G_{2}<4 \cdot 10^{8} \mathrm{MPa}$. The case $a=2 \mathrm{~m}$ and $b=1 \mathrm{~m}$ is not covered in Figure 4 (only valid for $b=2 \mathrm{~m}$ ). In this case, the plate buckle with 2 or 3 half-waves depending of the values of $G_{2}(t, T)$. In table 4 , the mode shape with two half-waves is presented.

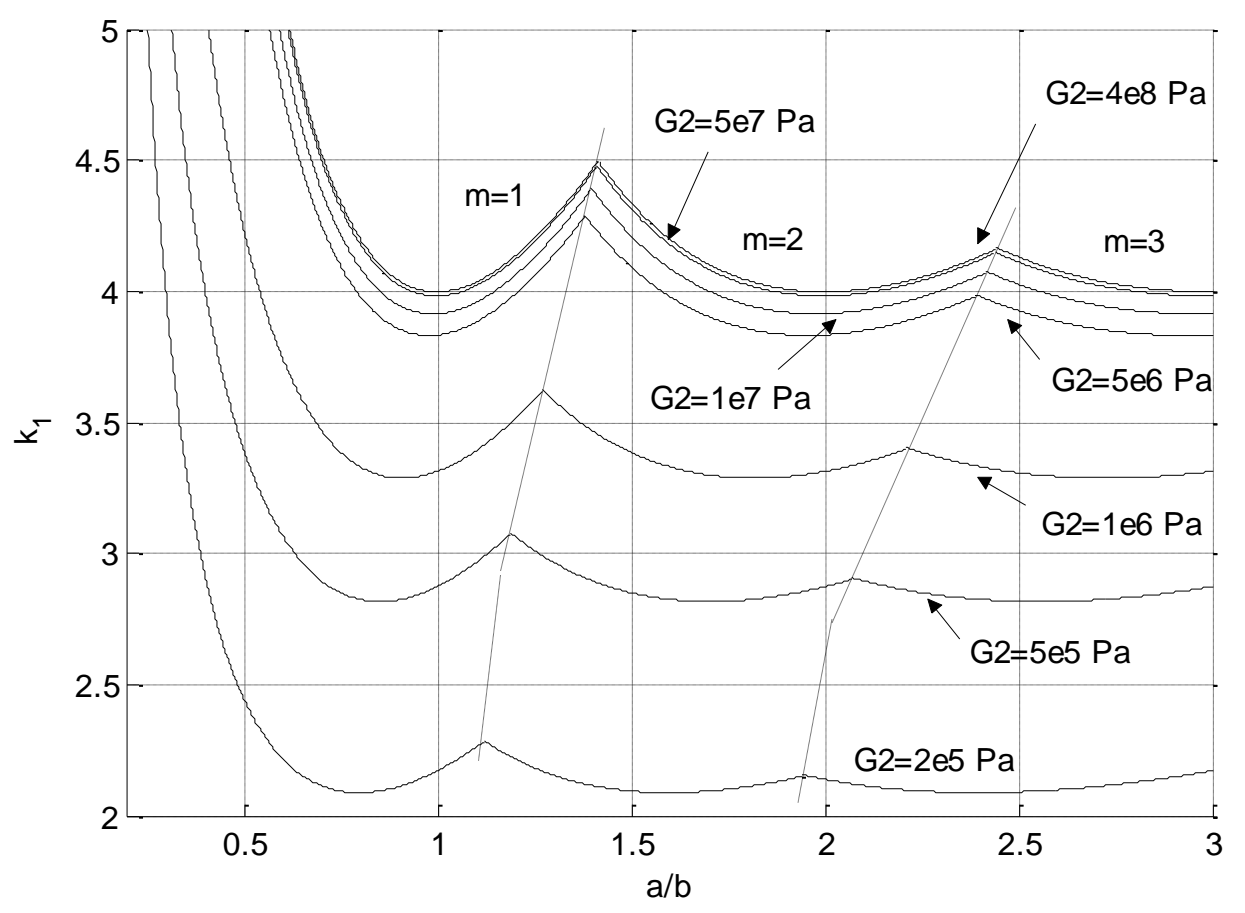

Figure 4. Parameter $k_{1}$ for a simple-supported laminated glass plate loaded in the $x$ direction (curves valid for plates with $b=2 \mathrm{~m}$ ). 


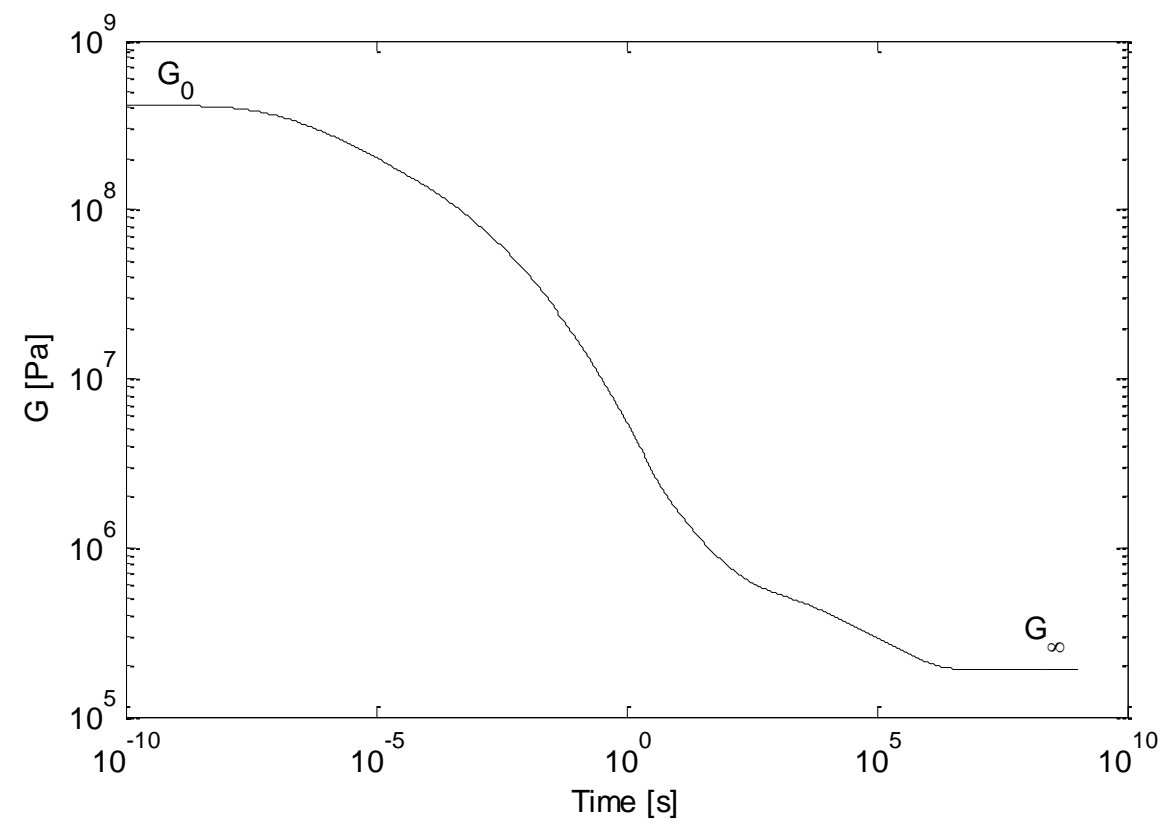

Figure 5. Shear modulus, G2, of the PVB interlayer.

The predicted critical loads $N_{\text {xcrit }}$ using Eq. (53) and the parameters presented in Table 3 are shown in Figure (6) for $a=1 m, b=2 m$, in Figure (7) for $a=2 m, b=2 m$ and in Figure (8) for $a=1 m, b=2 m$. The critical load of each case, obtained with the FEM, are also presented in Figures (6) to (8), respectively. It is inferred that Eq. (53) provides a good accuracy the error being less than $7.5 \%$ for the three cases considered in this section.

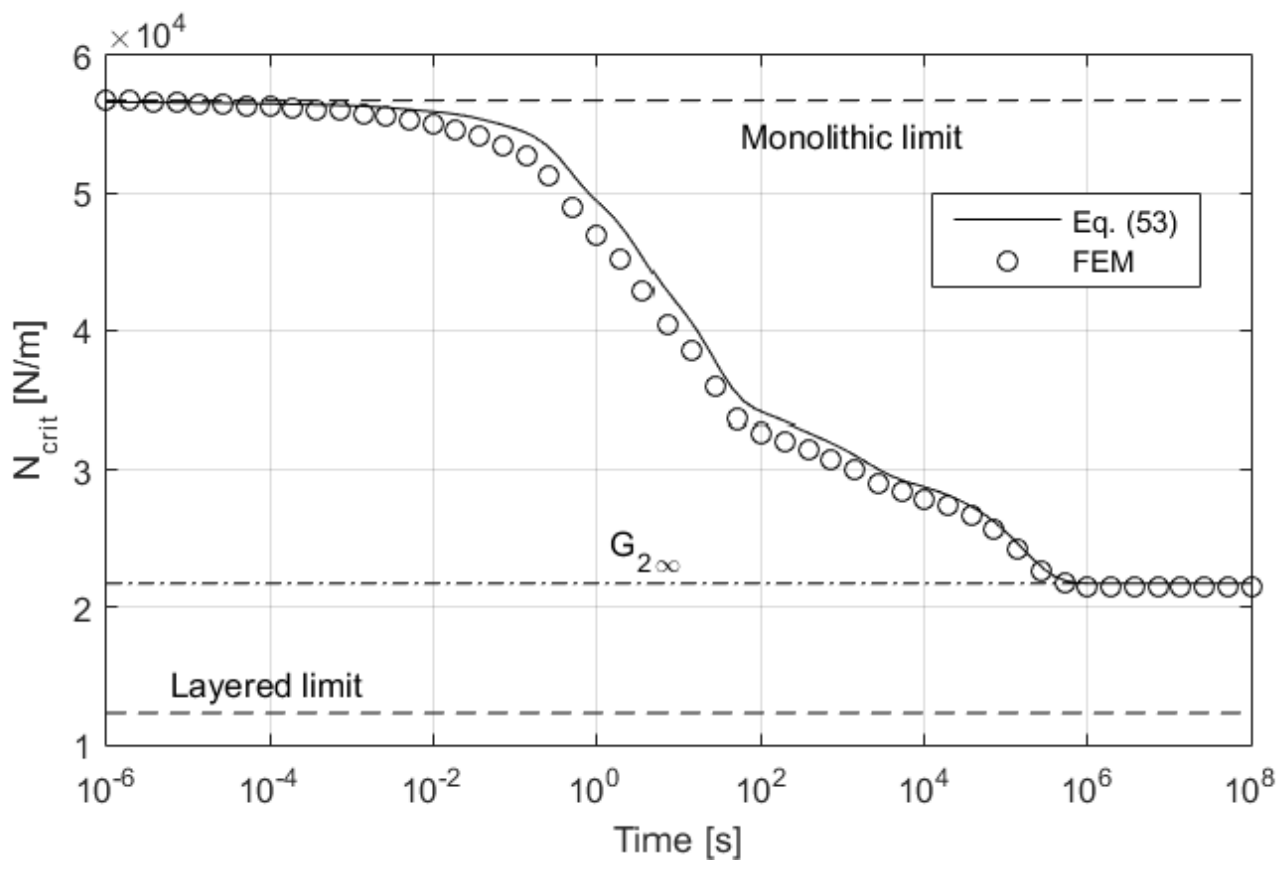


Figure 6. Critical load $N_{x c r i t}$ of a simply-supported laminated glass plate uniaxialy loaded in the $x$ direction for Temperature $T=20^{\circ} \mathrm{C}\left(a=1 \mathrm{~m}, \mathrm{~b}=2 \mathrm{~m}, H_{1}=H_{3}=\right.$ $\left.4 \mathrm{~mm}, \mathrm{H}_{2}=0.38 \mathrm{~mm}\right)$.

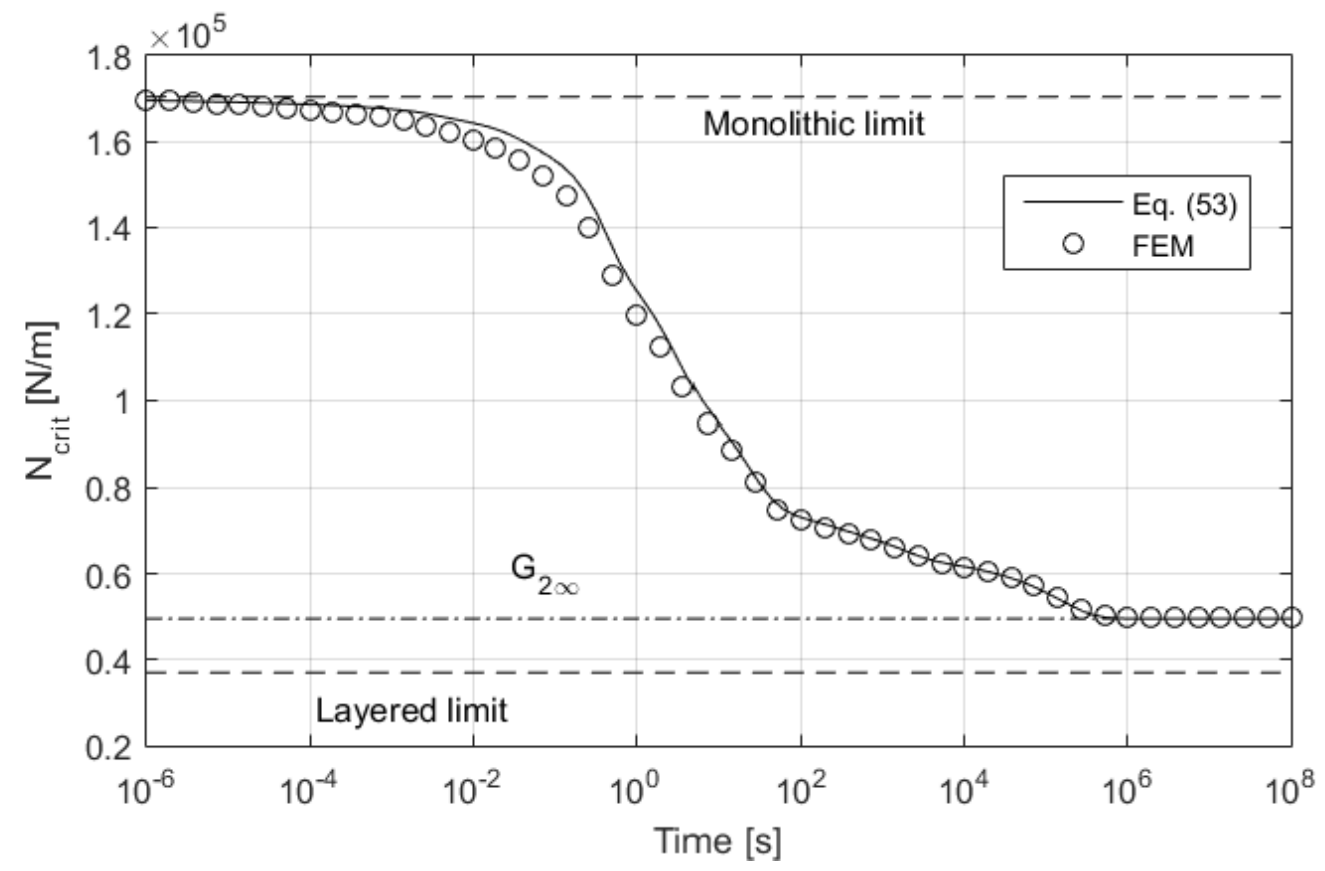

Figure 7. Critical load $N_{x c r i t}$ of a simply-supported laminated glass plate uniaxialy loaded in the $x$ direction for Temperature $T=20^{\circ} \mathrm{C}\left(a=2 \mathrm{~m}, b=1 \mathrm{~m}, H_{1}=H_{3}=\right.$ $\left.4 \mathrm{~mm}, \mathrm{H}_{2}=0.38 \mathrm{~mm}\right)$.

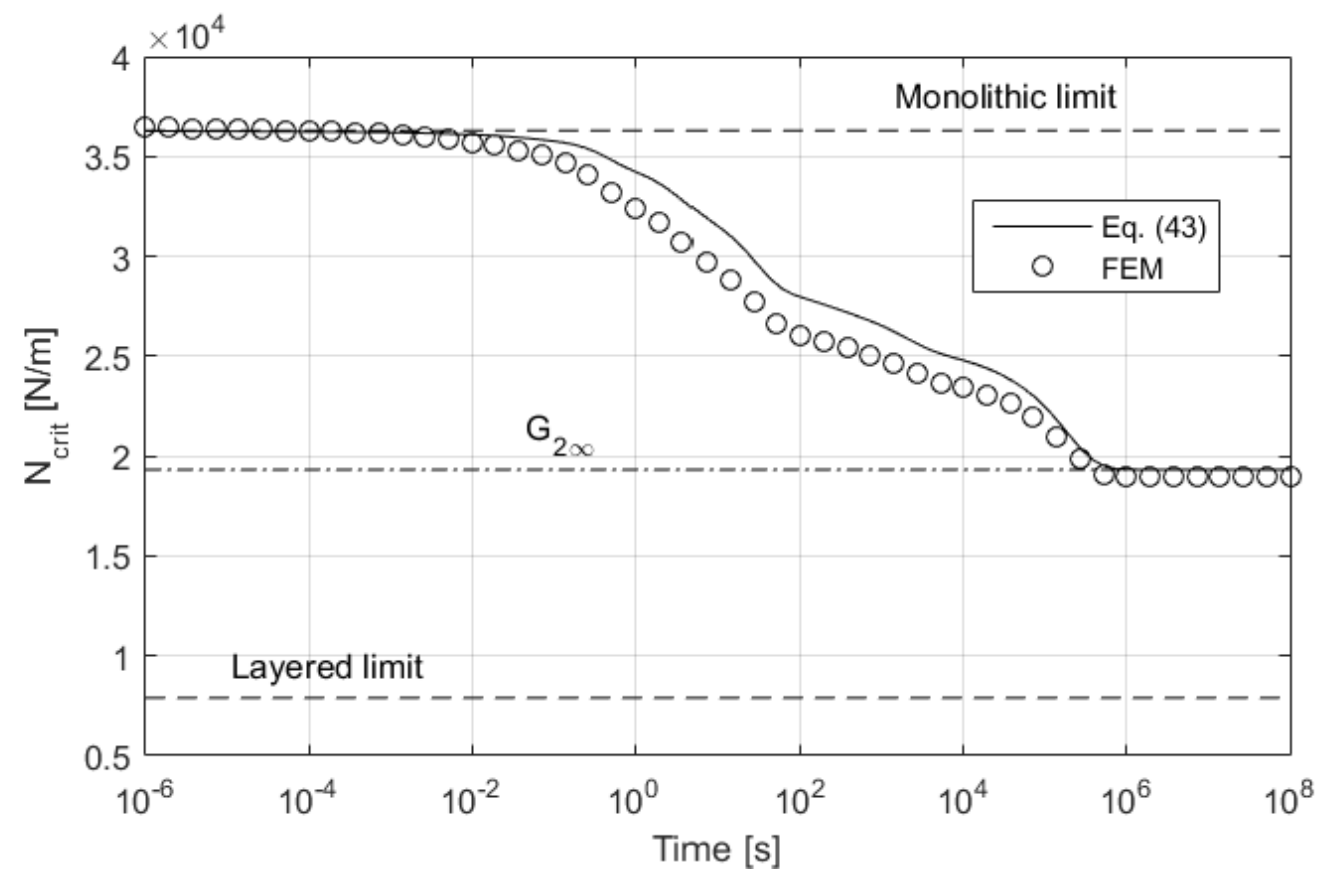


Figure 8. Critical load $N_{x c r i t}$ of a simply-supported laminated glass plate uniaxialy loaded in the $x$ direction for Temperature $T=20^{\circ} \mathrm{C}\left(a=2 \mathrm{~m}, b=2 \mathrm{~m}, H_{1}=H_{3}=\right.$ $\left.4 \mathrm{~mm}, \mathrm{H}_{2}=0.38 \mathrm{~mm}\right)$.

\subsection{Simply supported plate under biaxial compression}

For the case of a rectangular simply supported laminated glass plate subject to biaxial compression with loads $N_{x}$ and $N_{y}\left(N_{x y}=0\right)$, the same expression for the deflection shape given by Eq. (63) can be used. Moreover, it can be proved again that only one term of the series should be considered in calculating the critical values of $N_{x}$ and $N_{y}[20,21]$. Thus, the buckling mode shape is given by:

$$
g(x, y)=A_{m n} \sin \left(\frac{m \pi x}{a}\right) \sin \left(\frac{n \pi y}{b}\right)
$$

Applying the Energy method $[20,21]$ with the approximate buckling mode shape $g(x, y)$ the bending energy is given by:

$$
U_{b}=\frac{D_{e f f}(t, T)}{2} \int_{0}^{a} \int_{0}^{b}\left[\left(g_{x}^{\prime \prime}+g_{y}^{\prime \prime}\right)^{2}-2(1-v)\left(g_{x}^{\prime \prime} g_{y}^{\prime \prime}-\left(g_{x y}^{\prime \prime}\right)^{2}\right)\right] d x d y
$$

which after substitution of Eq. (76) results in:

$$
U_{b}=\frac{\pi^{4} D_{e f f}(t, T)}{8 a b} A_{m n}^{2}\left(\frac{m^{2} b}{a}+\frac{a n^{2}}{b}\right)^{2}
$$

The potential energy of the external loads is given by:

$$
U_{N}=-\frac{1}{2} \int_{0}^{a} \int_{0}^{b}\left[N_{x}\left(g_{x}^{\prime}\right)^{2}+N_{y}\left(g_{y}^{\prime}\right)^{2}\right] d x d y
$$

which leads to:

$$
U_{N}=-\frac{\pi^{2}}{8} A_{m n}^{2}\left(N_{x} \frac{m^{2} b}{a}+N_{y} \frac{a n^{2}}{b}\right)
$$

Minimization of the total energy gives: 


$$
N_{x} m^{2}+N_{y} \cdot n^{2}\left(\frac{a}{b}\right)^{2}=\frac{\pi^{2}}{b^{2}} D_{e f f}(t, T)\left(\frac{m^{2} b}{a}+\frac{a n^{2}}{b}\right)^{2}
$$

If the load $N_{y}$ is expressed as:

$$
N_{y}=\beta N_{x}
$$

the critical load $N_{x c r i t}$ can be obtained from:

$$
N_{x c r i t}=\frac{\pi^{2}}{b^{2}} \frac{\left(\frac{m b}{a}+\frac{a n^{2}}{m b}\right)^{2}}{\left(1+\beta \frac{a^{2} n^{2}}{b^{2} m^{2}}\right)} D_{e f f}(t, T)
$$

from which is obtained that the parameter $k$ is given by:

$$
k=\frac{\left(\frac{m b}{a}+\frac{a n^{2}}{m b}\right)^{2}}{\left(1+\beta \frac{a^{2}}{b^{2}} \frac{n^{2}}{m^{2}}\right)}
$$

With respect to parameter $\psi_{P}$, substitution of eq. (76) in eq. (56) gives:

$$
\psi_{P}=\frac{\pi^{2}}{b^{2}} k=\frac{\pi^{2}}{b^{2}} \frac{\left(\frac{m b}{a}+\frac{a n^{2}}{m b}\right)^{2}}{\left(1+\frac{a^{2}}{b^{2}} \frac{n^{2}}{m^{2}}\right)}
$$

The number of half waves in which the plate buckles into depends also on the parameter $\beta$. The parameter $k_{1}$ for a plate with $b=2 \mathrm{~m}$, and ratios $\beta=0.2$ and $\beta=1$ is presented in Figures 9 and 10, respectively, for different ratios $a / b$. 


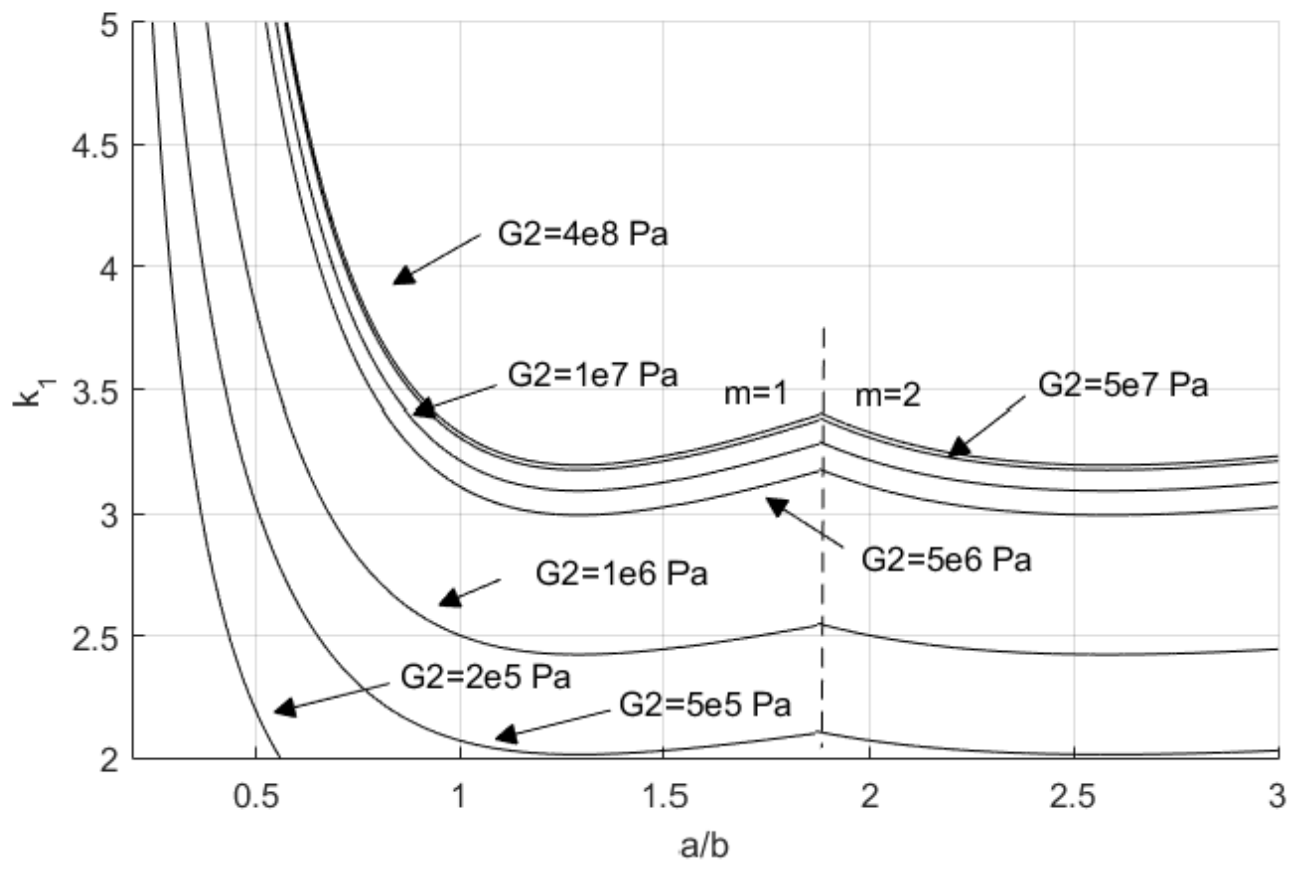

Figure 9. Parameter $k_{1}$ for a simply-supported laminated glass plate biaxially loaded with $N_{x}$ and $N_{y}=0.2 N_{x}$ (curves valid for $b=2 \mathrm{~m}$ ).

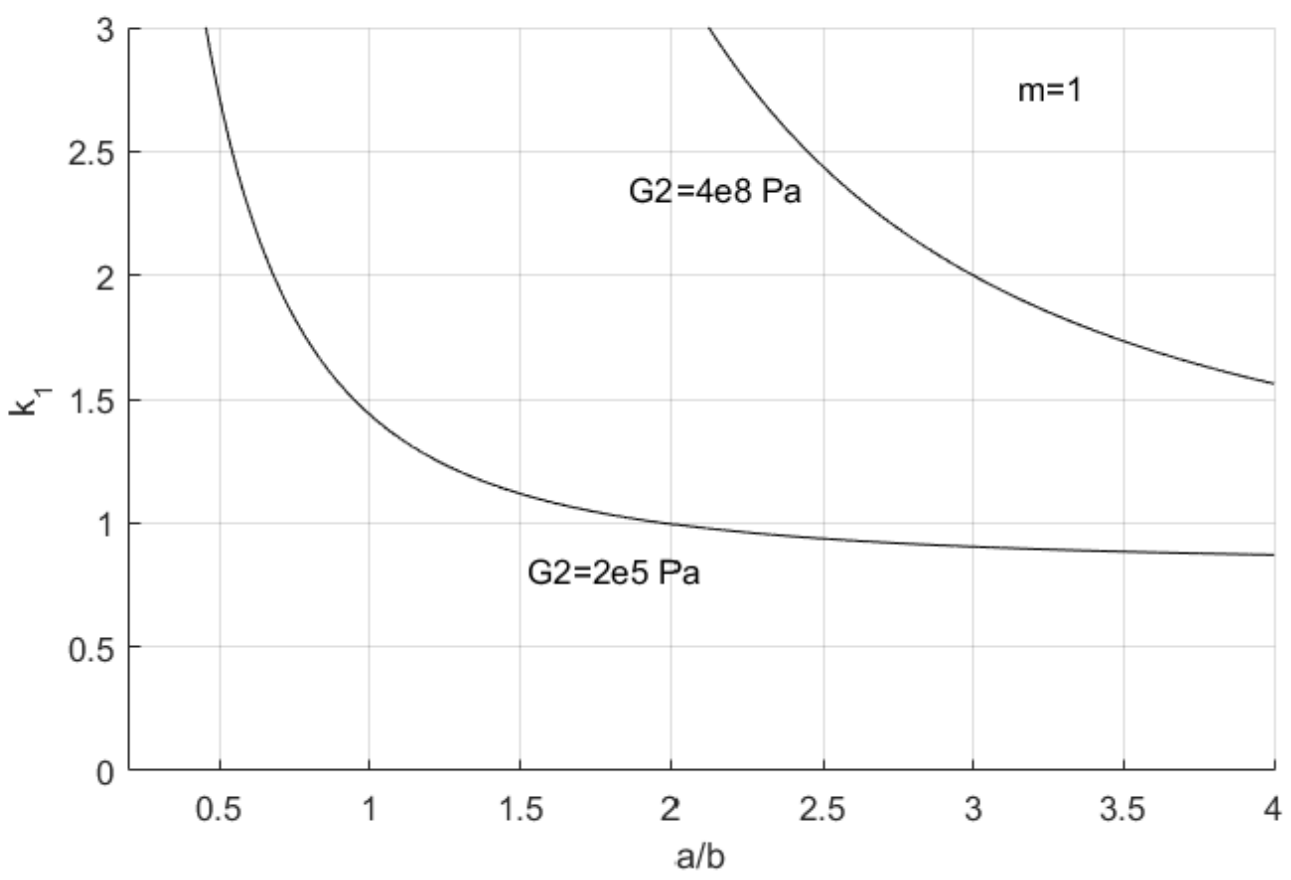

Figure 10. Parameter $k_{1}$ for a simply-supported laminated glass plate biaxially loaded with $N_{x}=N_{y}$ (curves valid for $b=2 \mathrm{~m}$ ).

The critical load of a square plate with $=b=2 m, N_{x}=N_{y}, \gamma=1$ and $m=n=1$ is predicted with Eq. (53) and shown in Figure (11). The critical load for this example was 
calculated with a FEM (see Figure (11)), following the same steps described previously. The maximum error between the numerical and the predicted critical load is $8.5 \%$.

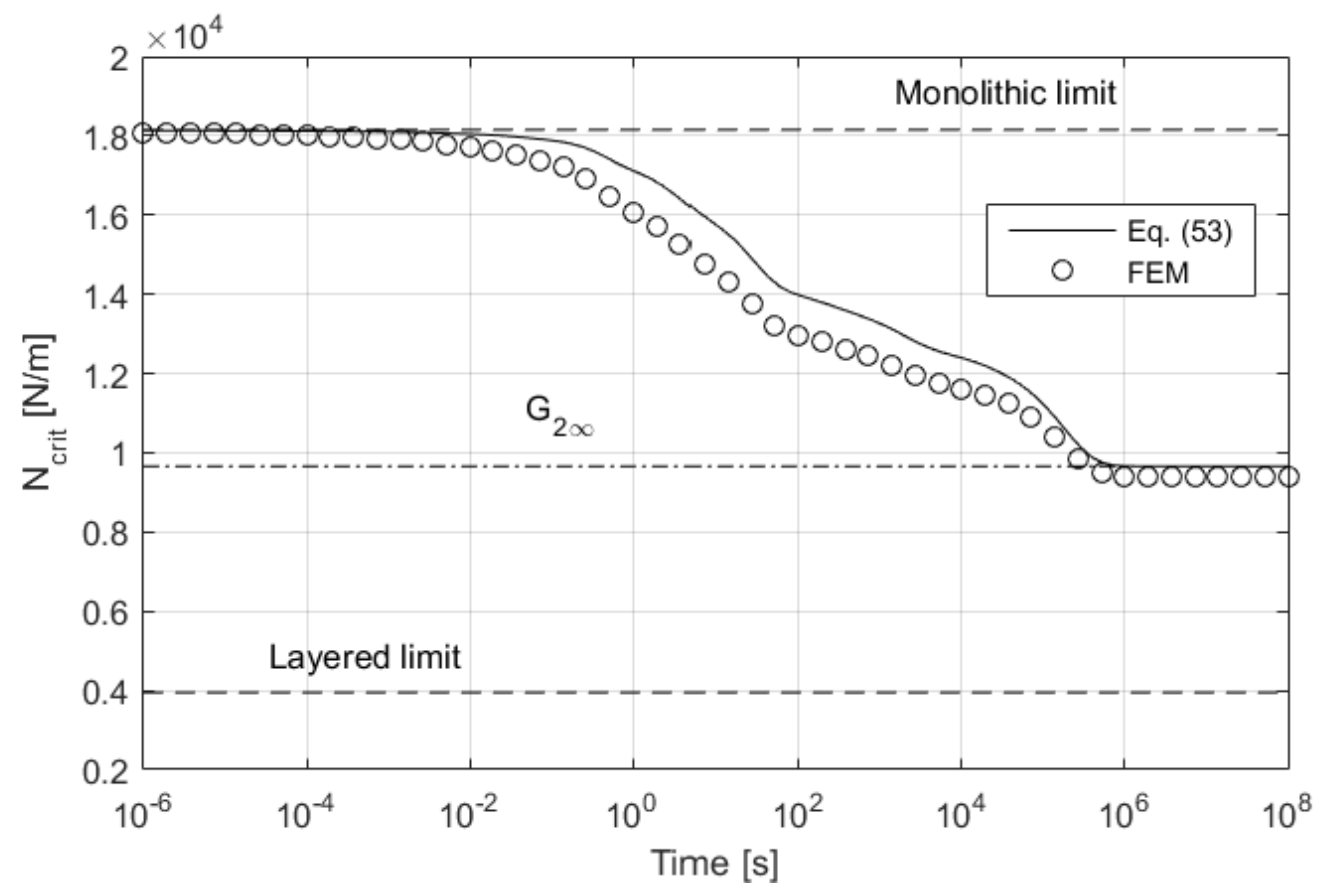

Figure 11. Critical load $N_{x c r i t}$ of a simply-supported laminated glass plate byaxially loaded for Temperature $T=20^{\circ} \mathrm{C}\left(a=b=2 \mathrm{~m}, H_{1}=H_{3}=4 \mathrm{~mm}, H_{2}=0.38 \mathrm{~mm}\right)$.

\subsection{Simply supported plate under in-plane shear}

We consider in this section the case of a simply supported plated subject to shearing forces $N_{x y}$ uniformly distributed along the four edges (see Figure 3 ). The boundary conditions are satisfied by taking for the deflection of the buckled plate the double series expression given by Eq. (63) [20, 21].

Using the Energy method with an approximate buckling mode shape $g(x, y)$ and considering $N_{x}=0$ and $N_{y}=0$ in eq. (30), the critical load can be obtained minimizing the equation:

$$
N_{x y c r i t}=\frac{\mathrm{D}(\mathrm{t}, \mathrm{T})_{\mathrm{eff}}}{2} \frac{\iint_{00}^{a b}\left[\left(g_{x}^{\prime \prime}+g_{y}^{\prime \prime}\right)^{2}-2(1-v)\left(g_{x}^{\prime \prime} g_{y}^{\prime \prime}-\left(g_{x y}^{\prime \prime}\right)^{2}\right)\right] d x d y}{\iint_{00}^{a b}\left(g_{x}^{\prime} g_{y}^{\prime}\right) d x d y}
$$

from which: 


$$
\frac{\pi^{2} k}{b^{2}}=\frac{\frac{1}{2} \iint_{00}^{a b}\left[\left(g_{x}^{\prime \prime}+g_{y}^{\prime \prime}\right)^{2}-2(1-v)\left(g_{x}^{\prime \prime} g_{y}^{\prime \prime}-\left(g_{x y}^{\prime \prime}\right)^{2}\right)\right] d x d y}{\iint_{00}^{a b}\left(g_{x}^{\prime} g_{y}^{\prime}\right) d x d y}
$$

If eq. (62) is substituted in eq. (87), the later becomes:

$$
\frac{\pi^{2} k}{b^{2}}=\frac{a b}{32} \frac{\sum_{m=1}^{\infty} \sum_{n=1}^{\infty} A_{m n}^{2}\left(\frac{\pi^{2} m^{2}}{a^{2}}+\frac{\pi^{2} n^{2}}{b^{2}}\right)^{2}}{\sum_{m=1}^{\infty} \sum_{n=1}^{\infty} \sum_{p=1}^{\infty} \sum_{q=1}^{\infty} A_{m n} A_{p q} \frac{m n p q}{\left(m^{2}-p^{2}\right)\left(q^{2}-n^{2}\right)}}
$$

where $m, n, p$ and $q$ are such integers that $m \pm p$ and $n \pm q$ are odd numbers.

For short elastic monolithic plates $(a / b<2)[21]$ the minimum value $N_{x y c r i t}$ is obtained when $m+n$ are even numbers. With respect to the parameter $\psi_{p}$, it can be calculated from:

$$
\psi_{P}=\frac{\iint_{00}^{a b}\left[\left(g_{x}^{\prime \prime}+g_{y}^{\prime \prime}\right)^{2}-2(1-v)\left(g_{x}^{\prime \prime} g_{y}^{\prime \prime}-\left(g_{x y}^{\prime \prime}\right)^{2}\right)\right] d x d y}{\iint_{00}^{a b}\left[\left(g_{x}^{\prime}\right)^{2}+\left(g_{y}^{\prime}\right)^{2}\right] d x d y}
$$

Substitution of Eq. (62) in eq. (89, leads to:

$$
\psi_{P}=\frac{\frac{a b}{4} \sum_{m=1}^{\infty} \sum_{n=1}^{\infty} A_{m n}^{2}\left(\frac{\pi^{2} m^{2}}{a^{2}}+\frac{\pi^{2} n^{2}}{b^{2}}\right)^{2}}{\frac{1}{4} \sum_{m=1}^{\infty} \sum_{n=1}^{\infty} A_{m n}^{2}\left(\pi^{2} m^{2} \frac{b}{a}+\pi^{2} n^{2} \frac{a}{b}\right)}
$$

In monolithic elastic plates [21] a good accuracy is obtained considering the first five terms ( $m+n$ even numbers), i.e. $A_{11}, A_{22}, A_{13}, A_{31}$ and $A_{33}$. With this assumption, the buckling deflection shape is given by:

$$
g(x, y),=\sum_{m=1,3} \sum_{n=1,3} A_{m n} \sin \left(\frac{m \pi x}{a}\right) \sin \left(\frac{n \pi y}{b}\right)
$$

where [21]:

$$
A_{11}=-\frac{4}{9} \frac{\gamma^{2}}{\lambda\left(1+\gamma^{2}\right)^{2}} A_{22}
$$




$$
\begin{aligned}
& A_{22}=-\frac{25}{36} \frac{\lambda\left(9+9 \gamma^{2}\right)^{2}}{\gamma^{2}} A_{33} \\
& A_{13}=\frac{4}{5} \frac{\gamma^{2}}{\lambda\left(1+9 \gamma^{2}\right)^{2}} A_{22} \\
& A_{13}=\frac{4}{5} \frac{\gamma^{2}}{\lambda\left(9+\gamma^{2}\right)^{2}} A_{22} \\
& \lambda^{2}=\frac{\gamma^{4}}{81\left(1+\gamma^{2}\right)^{4}}\left(1+\frac{81}{625}+\frac{81}{25}\left(\frac{1+\gamma^{2}}{1+9 \gamma^{2}}\right)^{2}+\frac{81}{25}\left(\frac{1+\gamma^{2}}{9+\gamma^{2}}\right)^{2}\right)
\end{aligned}
$$

The parameters $k$ and $k_{\psi}$ are shown in Figure 12 for different ratios $0.5<a / b<2$ whereas the parameter $k_{1}$ is shown in Figure 13 for different ratios $a / b$ and different values of $G_{2}(t, T)$.

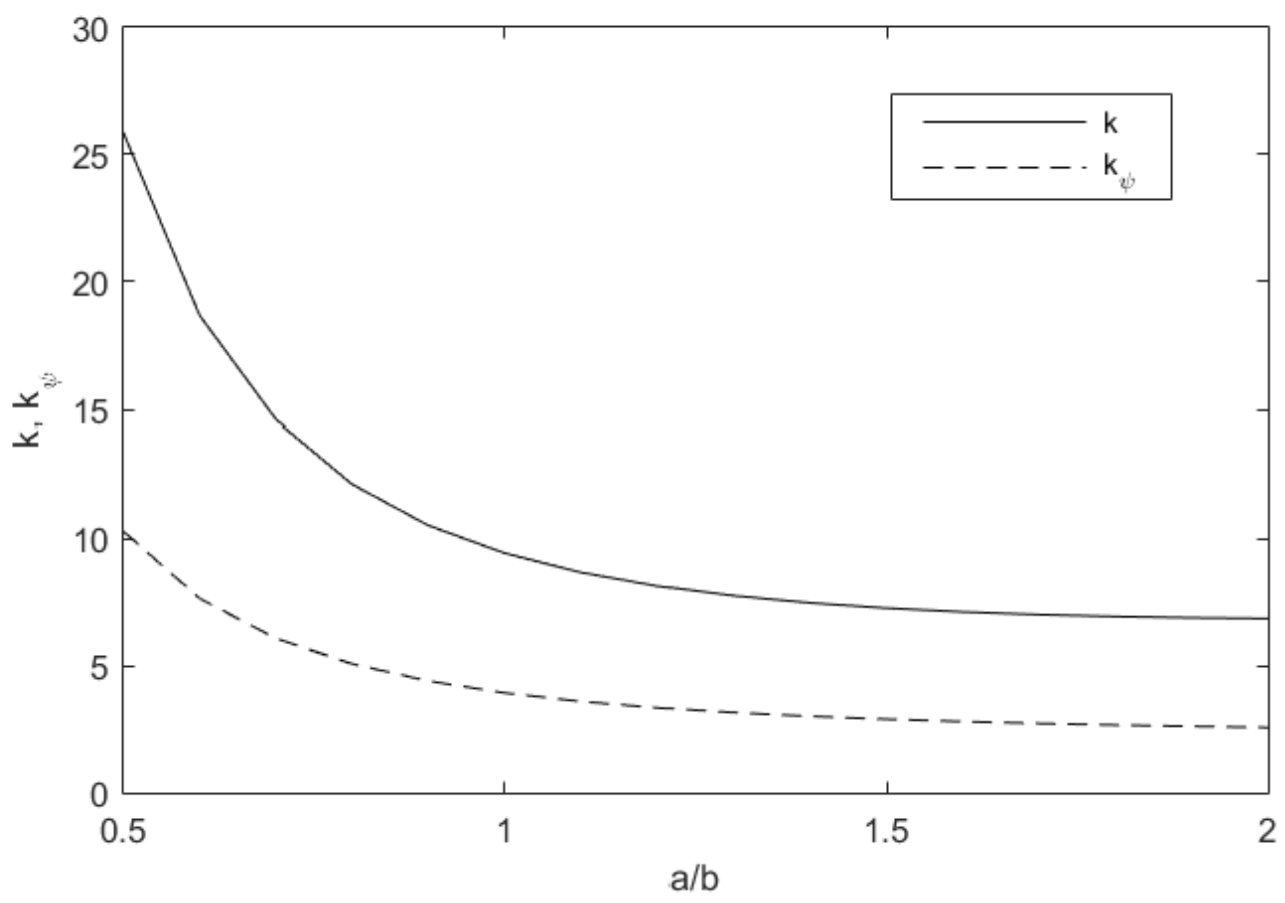

Figure 12. Parameters $k$ and $k_{\psi}$ for a simply-supported laminated glass subject to inplane shear. 


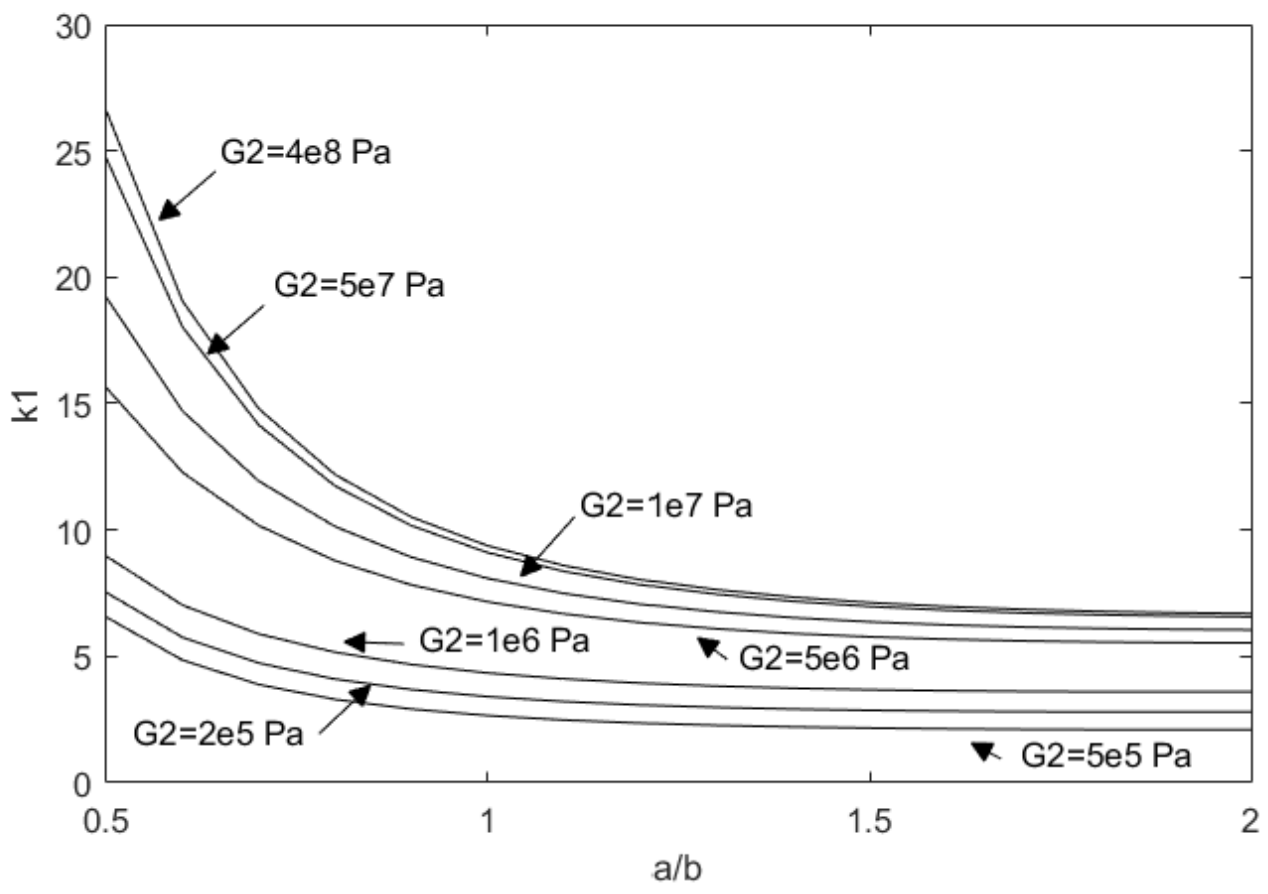

Figure 13. Parameters $k_{1}$ for a simply-supported laminated glass subject to in-plane shear (valid for $b=2 \mathrm{~m}$ ).

The critical load of a square plate with $a=b=2 m$ was predicted with Eq. (63) using the parameters $k$ and $k_{\psi}$ shown in Figure 12 and it is presented in Figure 14 together with critical load obtained with a FEM. The maximum error between the numerical and the predicted is less that $10 \%$.

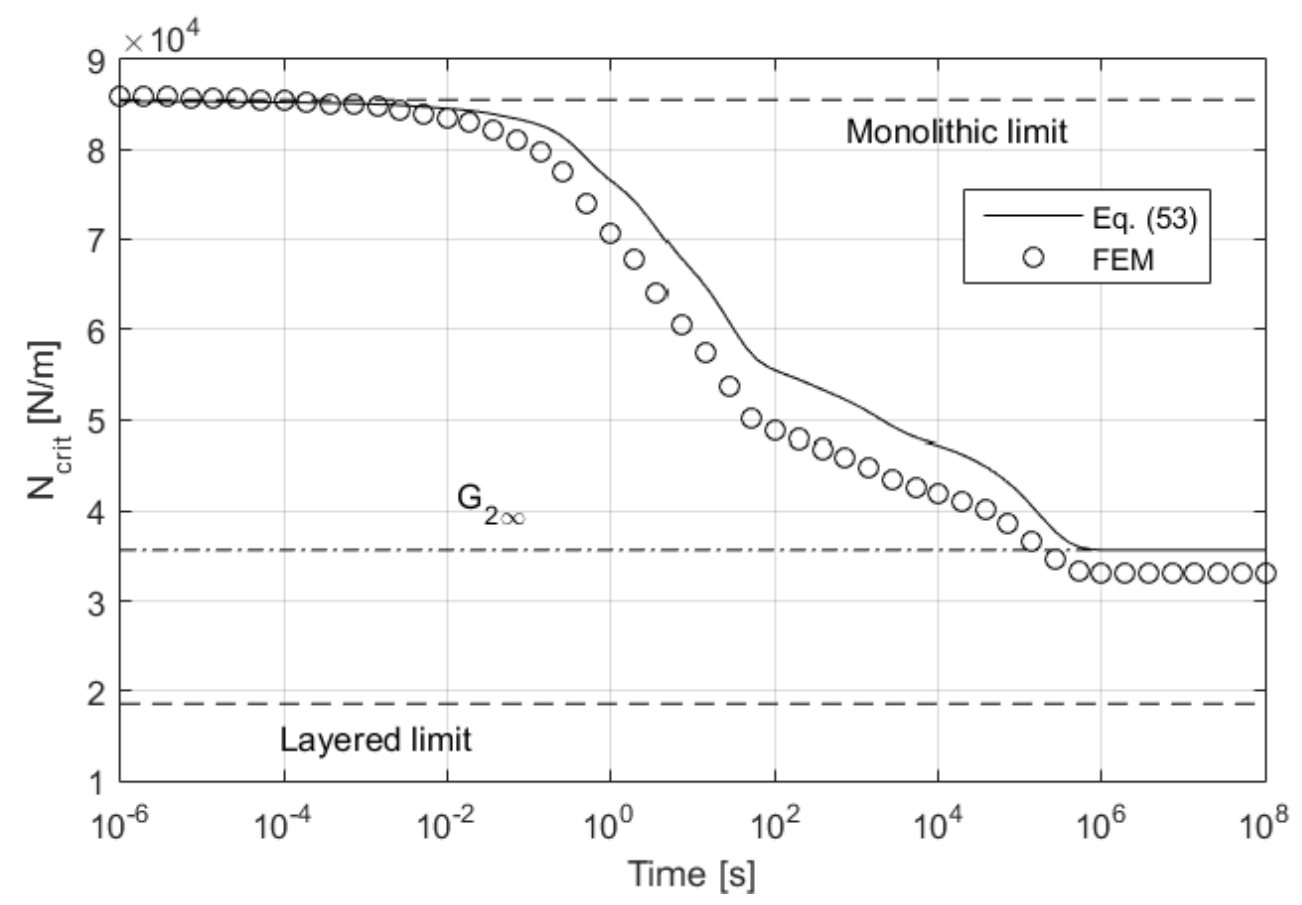


Figure 14. Critical load $N_{x c r i t}$ of a simply-supported laminated glass plate subjected to in-shear loading for Temperature $T=20^{\circ} \mathrm{C}\left(a=b=2 \mathrm{~m}, H_{1}=H_{3}=4 \mathrm{~mm}, \mathrm{H}_{2}=\right.$

$0.38 \mathrm{~mm})$.

\section{CONCLUSIONS}

Structural stability is a design criterion to be considered when laminated glass elements are subject to compressive loads. The critical load of a laminated glass plate is time and temperature dependent due to the viscoelastic behavior exhibited by the polymeric interlayers. However, in order to avoid failures due to buckling, the compressive load must be less than the critical load given by the long-term limit of the interlayer shear modulus $G 2 \infty$, which means that the quasi-elastic solution [10, 17] can be used advantageously to calculate safe critical loads in laminated glass elements.

In this paper, an analytical expression (Eq. (53) ) to predict the critical load of laminated glass plates subject to different compressive loading conditions has been proposed, which has been derived extending the buckling theory of isotropic monolithic plates $[20,21]$ to laminated glass plates, using the concept of effective stiffness. This effective stiffness takes into account the time and temperature dependency of the polymeric interlayers.

The effective stiffness derived by Galuppi and Royer Carfagni [26] for laminated glass plates has been used with Eq. (53), which is dependent on the boundary conditions trough parameter $\psi_{P}$. However, the concepts of effective stiffness, effective thickness and effective Young's modulus can be used interchangeably with the same accuracy [13].

Moreover, it has been assumed that the buckling mode shapes of the laminated glass plate is equal to that of a monolithic plate subject to the same loading and with the same boundary conditions.

When using Eq. (53), two parameters, $k$ and $\psi P$, dependent of the boundary and loading conditions, have to be known. With respect to parameter $k$, the same expressions used in monolithic plates have been considered, which can be found in the classical books of structural stability $[20,21]$ for the most common boundary and loading conditions. As regards parameter $\psi_{P}$, the analytical expression derived by Galuppi and Royer Carfagni 
[26] has been used to determine the values of this parameter corresponding to the boundary and loading conditions considered in the paper.

Parameters $k$ and $\psi_{P}$ are dependent on the number of half-waves in which the plate buckles into through the parameters $m$ and $n$. Due to the fact that the shear modulus of the interlayer $G_{2}(t, T)$ is time and temperature dependent, when a plate is subject to a buckling, the number of half-waves of the buckling mode shape can change also with time and temperature. This can be observed in Figures 4 and 9, where for some specific ratios $a / b$, the number of half-waves depend on the magnitude of the shear modulus of the interlayer.

The accuracy provided by Eq. (53) has been validated by numerical simulations. A finite element model of simply-supported laminated glass plates were assembled in ABAQUS. The plates were subject to uniaxial, biaxial and in plane shear loadings at a temperature $T=20^{\circ} \mathrm{C}$. It has been proved that the discrepancies between the numerical and the analytical results are less than $10 \%$ for all the boundary and loading conditions considered in the simulations, which demonstrates that Eq. (53) can predict with a good accuracy the buckling critical load of a laminated glass plates. Moreover, the monolithic limit and the long-term limit, corresponding to the interlayer shear modulus $G_{2}^{\infty}$, are predicted with a good accuracy the error being less than 5\%

\section{ACKNOWLEDGEMENTS}

The financing support given by the Spanish Ministry of Economy and Competitiveness through the project BIA2014-53774-R is gratefully appreciated. 


\section{REFERENCES}

[1] Benninson, S., M.HX, Q. and Davies, P., High-performance laminated glass for structurally efficient glazing. Innovative Light-weight Structures and Sustainable Facades, Hong Kong, May, 2008.

[2] E.W. Kuenzi, W.S. Ericksen, and J.J. Zahn, Shear stability of flat panels of sandwich construction, Armed services technical information agency, Virginia 1975.

[3] G. Allen, H. Analysis and Design of Structural Sandwich Panels. Pergamon Press Ltd. London. 1969.

[4] Ventsel, E. and Krauthammer. Thin Plates and Shells: Theory: Analysis, and Applications. CRC Press, 2001.

[5] Lee, E, H. Stress Analysis in Viscoelastic Bodies. Q J Mech Appl Math 1955; 13:183190.

[6] Read WT. Stress Analysis for Compressible Viscoelastic Materials. J Appl Phys 1950; 21:671-674.

[7] Foraboschi, P., Analytical model for laminated-glass plate, Compos Part B-Eng, 2012;43(5):2094-2106.

[8] Foraboschi, P., Three-layered plate: Elasticity solution. Compos Part B-Eng, in press, 2014.

[9] Galuppi, L., and Royer-Carfagni, G.F., The design of laminated glass under timedependent load, Int J Mech Sci, 2012; 68:67-75.

[10] Galuppi, L., and Royer-Carfagni, G.F., Laminated beams with viscoelastic interlayer, Int J Solids Struct. 2012;49:2637-2645.

[11] Galuppi, L., and Royer-Carfagni, G.F., Effective Thickness of Laminated Glass Beams: New Expression via a Variational Approach, J Struct Eng, 2012;38:53-67. 
[12] López-Aenlle, M., Pelayo, F., Frequency Response of Laminated Glass Elements: Analytical Modelling and Effective Thickness, Appl Mech Rev, 2013;65(2), 020802 (13 pages).

[13] López-Aenlle, M., Pelayo, Dynamic effective thickness in laminated-glass beams and plates. Compos Part B-Eng. 2014; 67:332-347.

[14] Calderone, I., Davies, P.S., and Benninson, S.J., Effective Laminate Thickness for the Design of Laminated Glass. In: Glass Processing Days, Tampere, Finland, 2009

[15] Blaauwendraad, J., Buckling of laminated glass columns. HERON, 2007;52(1/2):147-218.

[16] Sattler, K., Stein, P., Ingenieurbauten 3, Theorie und Praxis, Springer-Verlag, Wien. 1974.

[17] Galuppi, L., and Royer-Carfagni, G.F., Buckling of three-layered composite beams with viscoelastic interaction. Compos Struct, 2014;107:512-521.

[18] Feldmann, M., Kasper, R. et al. Guidance for European Structural Desing of Glass Components. JCR Scientific and Policy Report, doi: 10.2788/5523, 2014.

[19] López-Aenlle, M. Pelayo, F., Ismael, G., García Prieto, M.A., Martín Rodríguez, A., and Fernández-Canteli, A. Buckling of laminated-glass beams using the effectivethickness concept. Compos Struct, 2016;137: 44-55.

[20] Chajes, A., Principles of Structural Stability Theory (Civil engineering and engineering mechanics series). Prentice Hall, 1974.

[21] Timoshenko, S.P., Gere, J.M. Theory of elastic stability. McGraw Hill, London, 1963.

[22] Abaqus User's Manual, Dassault Systémes Simulia Corp., Providence, Rhode Island, USA. 2018.

[23] Wölfel, E., Nachgiebiger Verbund Eine Näherungslösung und deren Anwendungsmöglichkeiten, In: Stahlbau, 1987;6:173-180. 
[24] Amadio, C., Bedon, C., Buckling Verification of Laminated Glass Elements in Compression. JCES. 2012; 1(3): 90-101.

[25] Amadio, Claudio and Bedon, Chiara. An equivalent thickness for buckling verification of laminated glass panels under in-plane shear loads. J Civ Eng Manag. 2013; 2:108-123.

[26] Galuppi, Laura \& Royer Carfagni, Gianni. The effective thickness of laminated glass plates. J Mech Mater Struct. 2012; 7:375-400.

[27] Pelayo, F., Lamela-Rey, M., Muniz-Calvente, M., López-Aenlle, M., Álvarez Vázquez, A., and Fernández-Canteli, A. Study of the time-temperature-dependent behaviour of PVB: Application to laminated glass elements. Thin Wall Struct, 2017;119: $324-331$.

[28] Fröling M., Persson K., Computational methods for laminated glass. J Eng Mech, 10.1061/(ASCE)EM.1943-7889.0000527, 2013; 780-79.

[29] F. Pelayo, M. López-Aenlle, G. Ismael, A. Fernández-Canteli. Buckling of multilayered laminated glass beams: Validation of the effective thickness concept. Compos Struct. 2017; 169: 2-9. 
Figure Captions

Figure 1. Sandwich beam with two external faces of thicknesses $H=H_{1}=H_{2}$ and one interlayer with thickness $\mathrm{H}_{2}$.

Figure 2. Rectangular monolithic plate subject to a compressive uniaxial loading in the $x$ direction.

Figure 3: Rectangular monolithic plate subject to loadings $N_{x}, N_{y}$ and $N_{x y}$.

Figure 4. Parameter $k_{1}$ for a simple-supported laminated glass plate loaded in the $x$ direction (curves valid for plates with $b=2 \mathrm{~m}$ ).

Figure 5. Shear modulus, G2, of the PVB interlayer.

Figure 6. Critical load $N_{x c r i t}$ of a simply-supported laminated glass plate uniaxialy loaded in the $x$ direction for Temperature $T=20^{\circ} \mathrm{C}\left(a=1 \mathrm{~m}, b=2 \mathrm{~m}, H_{1}=H_{3}=\right.$ $\left.4 \mathrm{~mm}, \mathrm{H}_{2}=0.38 \mathrm{~mm}\right)$.

Figure 7. Critical load $N_{x c r i t}$ of a simply-supported laminated glass plate uniaxialy loaded in the $x$ direction for Temperature $T=20^{\circ} \mathrm{C}\left(a=2 \mathrm{~m}, b=1 \mathrm{~m}, H_{1}=H_{3}=\right.$ $\left.4 \mathrm{~mm}, \mathrm{H}_{2}=0.38 \mathrm{~mm}\right)$.

Figure 8. Critical load $N_{x c r i t}$ of a simply-supported laminated glass plate uniaxialy loaded in the $x$ direction for Temperature $T=20^{\circ} \mathrm{C}\left(a=2 \mathrm{~m}, b=2 \mathrm{~m}, H_{1}=H_{3}=\right.$ $\left.4 \mathrm{~mm}, \mathrm{H}_{2}=0.38 \mathrm{~mm}\right)$.

Figure 9. Parameter $k_{1}$ for a simply-supported laminated glass plate biaxially loaded with $N_{x}$ and $N_{y}=0.2 N_{x}$ (curves valid for $b=2 \mathrm{~m}$ ).

Figure 10. Parameter $k_{1}$ for a simply-supported laminated glass plate biaxially loaded with $N_{x}=N_{y}$ (curves valid for $b=2 \mathrm{~m}$ ).

Figure 11. Critical load $N_{x c r i t}$ of a simply-supported laminated glass plate byaxially loaded for Temperature $T=20^{\circ} \mathrm{C}\left(a=b=2 \mathrm{~m}, H_{1}=H_{3}=4 \mathrm{~mm}, H_{2}=0.38 \mathrm{~mm}\right)$.

Figure 12. Parameters $k$ and $k_{\psi}$ for a simply-supported laminated glass subject to inplane shear.

Figure 13. Parameters $k_{1}$ for a simply-supported laminated glass subject to in-plane shear (valid for $b=2 m$ ). 
Figure 14. Critical load $N_{x c r i t}$ of a simply-supported laminated glass plate subjected to in-shear loading for Temperature $T=20^{\circ} \mathrm{C}\left(a=b=2 \mathrm{~m}, H_{1}=H_{3}=4 \mathrm{~mm}, \mathrm{H}_{2}=\right.$ $0.38 \mathrm{~mm})$. 
Table 1. Parameters $\psi_{\text {thin }}$ and $\gamma$ for simply supported beams.

\begin{tabular}{ccc}
\hline Beam & $\psi_{\text {thin }}$ & $\gamma$ \\
\hline Central point load & $12 / L^{2}$ & $1-\frac{\sinh \theta+\frac{(1-\cosh \theta)}{\tanh \theta+1 / \tanh \theta}}{\theta}$ \\
Distributed load & $9.6 / L^{2}$ & $1+\frac{2}{\theta^{2} \cosh \theta}(1-\cosh \theta)$ \\
\hline
\end{tabular}

Table 2. $\psi_{B}$ for the first buckling mode shape of a beam

\begin{tabular}{ccc}
\hline Boundary condition & $g(x)$ & $\psi_{B}$ \\
\hline Simply supported & $A \sin \left(\frac{\pi x}{L}\right)$ & $\frac{\pi^{2}}{L^{2}}$ \\
Cantilever & $A\left(1-\cos \left(\frac{\pi x}{2 L}\right)\right)$ & $\frac{\pi^{2}}{4 L^{2}}$ \\
Fixed-pinned & $A\left(\frac{x}{L}+1.02 \cdot \sin \left(\frac{\pi x}{0.699 L}\right)\right)$ & $\frac{\pi^{2}}{0.4886 L^{2}}$ \\
Fixed-fixed & $A\left(1-\cos \left(\frac{2 \pi x}{L}\right)\right)$ & $\frac{\pi^{2}}{0.25 L^{2}}$ \\
\hline
\end{tabular}

Table 3. Material properties for glass and PVB [27].

\begin{tabular}{|c|c|c|c|c|c|c|c|}
\hline \multicolumn{3}{|c|}{$\begin{array}{c}\text { Glass } \\
\left(H_{1}=H_{3}=4 \mathrm{~mm}\right)\end{array}$} & \multicolumn{5}{|c|}{$\begin{array}{c}\text { PVB } \\
\left(H_{2}=0.38 \mathrm{~mm}\right)\end{array}$} \\
\hline $\begin{array}{c}\mathrm{E} \\
\text { (Young's } \\
\text { Modulus) } \\
{[\mathrm{GPa}]}\end{array}$ & $\begin{array}{c}v \\
\text { (Poisson's } \\
\text { ratio) }\end{array}$ & $\begin{array}{c}\rho \\
\text { (Density) } \\
{\left[\mathrm{kg} / \mathrm{m}^{3}\right]}\end{array}$ & $\begin{array}{c}\mathrm{G}_{0} \\
\text { (Instantaneous } \\
\text { shear modulus) } \\
{[\mathrm{GPa}]}\end{array}$ & $\begin{array}{c}\mathrm{K} \\
\text { (Bulk } \\
\text { Modulus) } \\
{[\mathrm{GPa}]}\end{array}$ & $\begin{array}{c}v \\
\text { (Poisson's } \\
\text { ratio) }\end{array}$ & $\begin{array}{c}\rho \\
\text { (Density) } \\
{\left[\mathrm{kg} / \mathrm{m}^{3}\right]}\end{array}$ & $\begin{array}{cc}C_{1} \quad C_{2} \\
\text { (WLF: } T r e f=20 \mathrm{C} \text { ) }\end{array}$ \\
\hline 72 & 0.22 & 2500 & 0.3696 & 2 & 0.44 & 1030 & $12.60 \quad 74.46$ \\
\hline
\end{tabular}


Table 4. Parameters $k$ and $\psi_{P}$ for a simply supported laminated glass plate with different ratios $a / b$.

\begin{tabular}{|l|l|l|l|l|l|l|l|l|}
\hline $\mathrm{a}$ & $\mathrm{b}$ & $\frac{a}{b}$ & $\mathrm{~m}$ & $\mathrm{n}$ & $\mathrm{k}$ & $\psi_{P}$ & $k_{\psi}$ & Mode shape \\
\hline $\mathrm{m}]$ & {$[\mathrm{m}]$} & & & & & & & \\
\hline 1 & 2 & .5 & 1 & 1 & 6.25 & 12.34 & 5 & \\
\hline 2 & 2 & 1 & 1 & 1 & 4 & 4.93 & 2 & \\
\hline 2 & 1 & 2 & 2 & 1 & 4 & 19.74 & 2 & \\
\hline
\end{tabular}


